\title{
NUEVOS DATOS FAUNÍSTICOS, COROLÓGICOS Y BIOLÓGICOS SOBRE LOS CINÍPIDOS DEL ÁMBITO ÍBERO-BALEAR (HYMENOPTERA, CYNIPIDAE) *
}

\author{
J. L. Nieves-Aldrey $(* *)$
}

\begin{abstract}
RESUMEN
Se presenta la compilación de los resultados faunísticos inéditos, de los muestreos de cinípidos en la Península Ibérica e islas Baleares realizados por el autor a lo largo de los últimos 20 años. Se aportan 164 nuevas citas regionales de especies de cinípidos, distribuidas como sigue: Andalucía, 43; Aragón, 23; Asturias, 2; Cantabria, 6; Baleares, 5; Castilla y León, 8; Castilla La Mancha, 17; Cataluña, 1; Extremadura, 15; Galicia, 2; La Rioja, 9; Madrid, 9; Murcia, 3; Navarra, 14; País Valenciano, 4 y País Vasco, 3. Asimismo se mencionan 399 citas nuevas para 40 provincias españolas, que suponen un incremento del $63 \%$ sobre el total de 633 citas previas existentes e incrementos medios por provincia del $447 \%$. Entre las cifras de citas nuevas por provincias destacan 32 especies citadas por primera vez para la provincia de Cádiz, 28 para la de Jaén, 22 para Málaga, 20 para Albacete, 19 para Soria y 18 nuevas citas para Huesca. Por primera vez se aportan datos sobre la entomofauna de cinípidos ligada a Quercus lusitanica y a Quercus canariensis en Andalucía, listando 9 y 18 especies respectivamente.
\end{abstract}

Palabras clave: cinípidos, faunística, distribución, Cynipidae, Península Ibérica, Baleares.

\begin{abstract}
New faunistic, biological and distributional data on cynipids from the Iberian Península and Balearic Islands (Hymenoptera: Cynipidae)

A compilation of unpublished faunistic results are presented, corresponding to the sampling of cynipids in the Iberian Península and Balearic Islands carried out by the author along the last twenty years. 164 new regional cynipid records are presented as follows, 43 for Andalusia, 23 for Aragon, 2 for Asturias, 6 for Cantabria, 5 for Balearic, 8 for Castille Lion, 17 for Castille la Mancha, 1 for Catalonia, 15 for Extremadura, 2 for Galicia, 9 for La Rioja, 9 for Madrid, 3 for Murcia, 14 for Navarra, 4 for Valencian Country and 3 for Basque Country. 399 new records for 40 Spanish provinces are contributed, meaning an increase of $63 \%$ on previous record data and an increase mean for province of 447 per cent. Among the new record numbers stands out 32 new species records for Cádiz, 28 for Jaén, 22 for Malaga, 20 for Albacete, 19 for Soria and 18 new records for the province of Huesca. By first time data are given on the cynipid fauna associated to Quercus lusitanica and Quercus canariensis from south of Spain. Records of 9 species linked to the former and 18 species to the last are presented.
\end{abstract}

Key words: cynipids, faunistic, distribution, regional richness, Iberian Peninsula, Balearic Islands

* Trabajo subvencionado por la DGICYT, Proyectos Fauna Ibérica I, II, III y por la DGES, PB97-1241.
** $\quad$ Museo Nacional de Ciencias Naturales (CSIC). José Gutiérrez Abascal 2. Madrid 28006 


\section{Introducción}

La familia Cynipidae es, junto a la de los Figitidae, una de las dos principales familias de himenópteros cinipoides (Hym., Cynipoidea), superfamilia importante por su diversidad dentro de los grupos de Hymenoptera Apocrita, antiguamente incluidos en la sección Parasitica. Los cinípidos se singularizan con respecto al tipo de vida de los representantes de dichos grupos, casi todos parasitoides, por su fitofagia especializada, que comporta la inducción obligatoria de agallas morfológicamente complejas en distintos tipos de plantas. En la recientemente concluida monografía sistemática de esta familia de insectos, dentro de la serie Fauna Ibérica, se concluye que la fauna íbero-balear de Cynipidae está constituida por 29 géneros y 140 especies (NievesAldrey, en prensa).

Al iniciar, hace ya más de 10 años, el trabajo para la culminación de una monografía sobre los cinípidos ibéricos, el estado de conocimiento en que se encontraba la faunística y distribución geográfica de las especies era notoriamente insatisfactorio. Históricamente el estudio de los cinípidos ibéricos ha estado circunscrito fundamentalmente a Portugal, país natal de Rev. Silva Tavares, quien hasta hace 20 años figuraba como máximo y casi único exponente del estudio del grupo en nuestra área geográfica, con contadas excepciones (Cogolludo, 1921; Vilarrubia, 1936, 1956). Esta situación comenzó a paliarse con el inicio de los estudios propios, centrados fundamentalmente en la zona centro-occidental de España (NievesAldrey, 1982, 1983a, 1983b, 1985a, 1985c, 1988, 1989, 1990) y los de Juli Pujade en Cataluña (Pujade-Villar, 1984, 1985b, 1986a, 1986b, 1991). Sin embargo, grandes áreas del territorio íberobalear, incluyendo casi todo el Sur, Norte y Levante de España permanecían prácticamente inéditas en cuanto al conocimiento de su fauna de cinípidos.

El principal objetivo de este trabajo es corregir esta negativa situación (publicar todas las citas, novedades y datos faunísticos concretos que no pueden ser incluidos en detalle en la monografía de Fauna). Para ello se recopilan los resultados no publicados de las campañas de muestreo o colectas puntuales efectuadas por el autor en España, Portugal e Islas Baleares en los últimos 20 años, que incluyen por primera vez numerosas citas para las áreas deficientemente prospectadas antes mencionadas.

\section{Material y métodos}

Todo el material estudiado, insectos y agallas, ha sido colectado por el autor y se encuentra depositado en las colecciones del Museo Nacional de Ciencias Naturales de Madrid. Los muestreos consistieron fundamentalmente en transectos por el campo de duración variable, en los que se procedía a la recogida de agallas sobre las distintas plantas anfitrionas. Puntualmente se utilizaron otros métodos de muestreo, como barridos de la vegetación mediante red entomológica y captura directa de adultos en proceso de oviposición sobre dichas plantas hospedantes. Las agallas posteriormente mantenidas en las condiciones de laboratorio permitieron en la mayoría de los casos la obtención por emergencia de adultos de las especies de cinípidos inductoras y de los cinípidos inquilinos confirmando así, en el primer caso, la identificación preliminar basada tanto en la morfología específica de la agalla como en los datos de la planta hospedadora.

\section{Relación de especies}

A continuación se relacionan las especies estudiadas, con arreglo a la ordenación sistemática seguida en la monografía de Fauna Ibérica (NievesAldrey, en prensa). Para cada especie se comenta su distribución geográfica, citas previas en el ámbito íbero-balear y novedades faunísticas reseñables, normalmente la lista de provincias en las que la especie se cita por primera vez. La relación completa de registros faunísticos para cada especie, incluyendo datos de localidades, UTM, fechas de captura y datos de biología se compila en el apéndice final.

\section{AYLACINI}

Isocolus lichtensteini (Mayr, 1882)

Especie de distribución mediterránea que induce la formación de agallas en los tallos de especies de Centaurea (Asteraceae). Citada de Setúbal (Portugal) (Tavares, 1927a), de Castellón, Valencia y Ávila (Nieves-Aldrey, 1985a, 1985c) y de Lérida (Pujade-Villar, 1986a). Encontrada ahora en las provincias de Almería, Cádiz, Madrid, Mallorca y Zamora.

Isocolus scabiosae (Giraud, 1859)

Especie de amplia distribución europea, ligada a la formación de agallas en tallos y cabezuelas flo- 
rales de diversas especies de Centaurea. En España se ha citado en Asturias, Ciudad Real y Cuenca (Nieves-Aldrey, 1985a, Nieves-Aldrey, 1985c) y también en Andorra (Pujade-Villar, 1997). Encontrada adicionalmente en El Monte de El Pardo (Madrid).

\section{Isocolus fitchi (Kieffer, 1898)}

Especie mal conocida, citada solamente de Francia e Inglaterra, que forma agallas semisubterráneas en Centaurea scabiosa. En Portugal la especie fue citada por Tavares $(1905,1927 a)$, pero quizás es una identificación errónea. Posteriormente la especie es citada de Cuenca y Huesca (Nieves-Aldrey, 1985a). Hallada también en Arguis (Huesca).

Aulacidea laurae Nieves-Aldrey, 1992

Especie de la región mediterránea occidental que forma agallas en los aquenios de Scorzonera laciniata. Originalmente se describió de Venturada (Madrid) y más tarde se encontró en el sur de Francia. Son citas adicionales Arganda (Madrid) y La Armuña (Salamanca).

\section{Aulacidea follioti Barbotin, 1972}

Especie europea occidental que induce la formación de agallas en tallos de Sonchus asper (Asteraceae). En España se conoce en localidades de la provincia de León y Segovia (Nieves-Aldrey, 1988, 1989). Se agrega una nueva cita de Roncesvalles (Navarra).

\section{Aulacidea tragopogonis (Thomson, 1877)}

La distribución de esta especie, que forma agallas en los tallos de diversas especies de Tragopogon (Asteraceae), es amplia en Europa. En la Península Ibérica se ha citado tan sólo en las provincias de León y Madrid (Nieves-Aldrey, 1985a; 1988). Se cita de una nueva localidad en el sur de Madrid.

\section{Aulacidea hieracii (Linnaeus, 1758)}

Especie común, de amplia distribución en toda Europa. Origina agallas en tallos de distintas especies de Hieracium. En la Península Ibérica se ha citado en Portugal (Tavares, 1927a; Nieves-Aldrey, 1985a), en la zona centro de España (Sierras de la Peña de Francia y Guadarrama) (Nieves-Aldrey, 1985a, 1988), donde aparece localmente si bien no es abundante, y en Andorra (Pujade-Villar, 1998). Añadimos aquí citas de dos nuevas localidades de Madrid y Salamanca.

\section{Aulacidea subterminalis Niblett, 1946}

Especie de distribución europea que induce la formación de agallas características en los tallos estoloníferos o bajo la roseta de hojas de Hieracium pilosella (Asteraceae). En La Península Ibérica se conocía tan sólo en tres localidades de la Serranía de Cuenca y la Sierra de Gata (Nieves-Aldrey, 1985a). Agregamos una nueva cita de la sierra de Guadarrama en la Comunidad de Madrid.

\section{Aulacidea freesei Nieves-Aldrey, 1995}

Especie descrita recientemente junto a Phanacis zwolferi, obtenidas ambas a partir de agallas en tallos de Silybum marianum colectados en el sureste de Francia. En el Torcal de Antequera (Málaga) se han encontrado agallas idénticas sobre la misma planta que pudieran corresponder a esta especie o bien a $P$. zwolferi y suponen su primera cita para la Península Ibérica.

\section{Neaylax verbenacus (Nieves-Aldrey, 1988)}

Especie conocida tan sólo de Italia y España. Induce la formación de agallas características en el ovario de las flores de Salvia verbenaca y Salvia pratensis L. (Lamiaceae). En la Península Ibérica se ha citado en varias localidades de la provincia de Madrid y en la Serra de Arrábida, en Portugal (NievesAldrey, 1988). A estas citas se añaden otras nuevas para las provincias de Albacete, Guadalajara y Jaén.

\section{Xestophanes potentillae (Retzius, 1783)}

Especie extendida por casi toda Europa asociada con Potentilla reptans (Rosaceae), planta en la que induce la formación de agallas en estolones y rizomas. En la Península Ibérica había sido citada en las provincias de Salamanca, Guipúzcoa, Valencia, Madrid y Guadalajara (Nieves-Aldrey, 1985a, 1986, 1989, 1995a). La distribución ibérica conocida se amplía ahora bastante al citarla por primera vez de las provincias de Huesca, León, Navarra y Zamora.

Xestophanes brevitarsis (Thomson, 1877)

Especie que se distribuye por Europa occidental, asociada exclusivamente con Potentilla erecta (= tormentilla) (Rosaceae). Tavares (1930a) la citó en Portugal y, mucho más recientemente, la especie se encontró nuevamente en Portugal (Serra da Estrela) y en varias localidades de España, en las provincias de Lérida, Madrid, Salamanca y Segovia (Nieves-Aldrey, 1985a, 1989). Adicionalmente se cita de Selva de Oza (Huesca). 
Barbotinia oraniensis (Barbotin, 1964)

Especie de distribución mediterránea que induce agallas en las cápsulas fructíferas de diversas especies de Papaver (Papaveraceae). En la Península Ibérica se había citado únicamente en las provincias de Guadalajara, Madrid y Salamanca (Nieves-Aldrey, 1985a, 1989); a estas citas se añaden las localidades de lagunas de Ruidera (Ciudad Real), puerto de Despeñaperros (Jaén) y Sierra Nevada (Granada).

\section{Aylax minor Hartig, 1840}

Común en toda Europa. Ligada también a especies de Papaver en cuyas cápsulas induce la formación de agallas. En la Península Ibérica se ha citado en distintas localidades del centro y noreste de España donde es relativamente abundante (Cogolludo, 1921; Nieves-Aldrey, 1985a, 1989. Pujade-Villar, 1986a, 1998). Se suman nuevas citas de Serra de Arrábida (Portugal), El puerto de Despeñaperros (Jaén), Pampaneira (Granada) y Posada de Valdeón (León).

\section{Aylax papaveris (Perris, 1840)}

Al igual que $A$. minor es una especie común en toda Europa, que forma agallas en las cápsulas fructíferas de varias especies de amapolas. En la Península Ibérica se ha citado en Portugal: Algarve, Serra da Estrela y Setúbal (Tavares, 1927a). En España hay citas antiguas en Madrid (Cogolludo, 1921) y Orense (Tavares, 1927a). Más recientemente se ha citado en el centro y noreste de España (Nieves-Aldrey, 1985a, 1985c, 1989). A estas citas se agregan otras nuevas de las provincias de Ciudad Real, León, Málaga y Zamora.

\section{Iraella luteipes (Thomson, 1877)}

Especie de amplia distribución en Europa y Asia Menor, aunque escasamente citada, ligada específicamente a la adormidera (Papaver somniferum). Su presencia en la Península Ibérica se ha detectado muy recientemente, y se conocía una única cita publicada de la localidad madrileña de Rivas Vaciamadrid (Nieves-Aldrey, 1994). A esta cita se suma una nueva de Valdemorillo, en la misma provincia.

\section{Timaspis phoenixopodos Mayr, 1882}

Elemento del Mediterráneo occidental. Forma agallas en los tallos de Lactuca viminea (L.) (Asteraceae). Citada en la zona centro de España en: Madrid, Salamanca y Toledo (Cogolludo, 1921;
Nieves-Aldrey, 1985a, 1989) y también en la provincia de Barcelona y Andorra (Pujade-Villar, 1986a; 1998). En Portugal se conoce en Tras-osMontes (Tavares, 1927b). Una cita adicional es Albarracín (Teruel).

\section{Timaspis cichorii (Kieffer, 1909)}

Especie mal conocida, citada en raras ocasiones, pero de amplia distribución en Europa. Las larvas viven en los tallos de Cichorium intybus L. (Asteraceae) en los cuales no producen hipertrofia. La única cita existente de la especie en la Península Ibérica correspondía a la localidad madrileña de Perales de Tajuña (Nieves-Aldrey, 1985c). Añadimos la vecina localidad de Arganda y la primera cita en Andalucía, en Villaluenga del Rosario (Cádiz).

\section{Phanacis centaureae Förster, 1860}

Especie ampliamente distribuida en Europa desde la Península Ibérica hasta Rusia. Se obtiene a partir de tallos de distintas especies de Centaurea (Asteraceae), en España principalmente de Centaurea ornata, C. scabiosa y C. aspera. En la Península Ibérica se ha citado en distintas provincias españolas de la zona centro: Ciudad Real, Guadalajara, León, Madrid y Salamanca (Tavares, 1927a; Nieves-Aldrey, 1985c, 1989). A estas referencias se añaden nuevas citas de las provincias de Cuenca y Valladolid.

Phanacis caulicola (Hedicke, 1939)

La especie se describió de material colectado en Inglaterra y posteriormente sólo se ha citado en Polonia y en España, en la provincia de Valladolid (Nieves-Aldrey, 1988). La larva vive en el interior de los tallos de Picris echioides L. (= Helmintia echioides) (Asteraceae). Se agrega una segunda cita ibérica en la localidad de Valdenoches (Guadalajara), donde es localmente abundante.

Phanacis hypochoeridis (Kieffer, 1887)

Especie frecuente, de amplia distribución en el paleártico occidental, que induce agallas en los tallos de especies de Hypochoeris (Asteraceae). En la Península Ibérica se ha citado en numerosas localidades de Portugal (Beira Baixa, Coimbra, Douro, Porto, Geres, Vianna do Castelo) (Tavares, 1927a). En España se conoce en un gran número de regiones: Andalucía, Castilla, Cataluña, Galicia y Madrid (Lázaro e Ibiza, 1917; Cogolludo, 1921; Tavares, 1927a; Nieves-Aldrey, 1985a, 1989) y también en Andorra (Pujade-Villar, 1998). Se 
amplía su distribución a las provincias de Albacete, Jaén, Lérida, Málaga y Palencia.

\section{SYNERGINI}

Ceroptres clavicornis Hartig, 1840

Especie de amplia distribución en Europa, inquilina de agallas de otros cinípidos en especies de Quercus. Las únicas citas en la Península Ibérica se refieren a varias provincias del centro de España y de Cataluña (Pujade-Villar y Nieves-Aldrey, 1993). Se cita por primera vez para Andalucía, en la provincia de Málaga y para Aragón en la de Huesca.

Periclistus brandtii (Ratzeburg, 1832)

Especie inquilina en agallas de Diplolepis rosae y D. mayri sobre distintas especies de Rosa, ampliamente distribuida en Europa. En la Península Ibérica se citó primero en Lousa (Portugal) (Tavares, 1920) y posteriormente en España, en distintas localidades de las provincias de Salamanca, Madrid y Guadalajara así como en Cataluña (Pujade-Villar, 1983; Nieves-Aldrey, 1984, 1986, 1989). Se cita por vez primera en Andalucía, en la Sierra del Pinar (Cádiz).

\section{Saphonecrus connatus (Hartig, 1840)}

Especie común y de amplia distribución en Europa. En la Península Ibérica también es una especie relativamente frecuente, que vive inquilina en agallas de distintas especies de cinípidos asociadas con Quercus caducifolios o marcescentes. Tavares (1920) la cita en São Fiel y Torres Vedras (Portugal) y en Pontevedra (España). Pujade-Villar y Nieves-Aldrey (1990) la mencionan del centro y oeste de España. Se registra por primera vez para Aragón, en el puerto de Orihuela (Teruel).

Saphonecrus lusitanicus (Tavares, 1902)

Especie del Mediterráneo occidental ligada, como inquilina, a cinípidos del género Plagiotrochus que forman agallas sobre Quercus esclerófilos perennifolios (Quercus ilex, Q. coccifera y $Q$. suber). En el área íbero-balear se ha citado en Portugal, en Torres Vedras (Tavares, 1920), y en España se conoce en las provincias de Barcelona, Ciudad Real, Gerona, Guadalajara, Lérida, Madrid, Salamanca, Zamora y Zaragoza (Nieves-Aldrey, 1982, 1986; Pujade-Villar y Nieves-Aldrey, 1990; Pujade-Villar y Ros-Farré, 1998). Por primera vez se cita de El Algarve portugués y de Andalucía y, por segunda vez, de Aragón.

\section{Synophrus politus Hartig, 1843}

Se distribuye por el centro y sur de Europa, norte de África y Asia Menor. En España es una especie relativamente común, donde sigue el área de distribución del alcornoque (Quercus suber). Citada de las provincias de Cádiz, Gerona, Madrid, Pontevedra y Salamanca (Tavares, 1927a; PujadeVillar, 1986a; Nieves-Aldrey, 1982, 1989). Se menciona por primera vez de El Algarve portugués y de las provincias de Ávila, Cáceres, Jaén, Lugo y Toledo.

Synergus crassicornis (Curtis, 1838)

Ampliamente distribuida en Europa, citada como inquilina en agallas de 15 especies de cinípidos (Nieves-Aldrey y Pujade-Villar, en prensa). En el área ibérica se conoce de Aragón, Andalucía, distintas localidades catalanas, Andorra y varias provincias del centro de España (Nieves-Aldrey, 1986, 1989; Nieves-Aldrey y Pujade-Villar, 1986; Pujade-Villar, 1992; Pujade-Villar y Ros-Farré, 1998). Tavares (1920) la citó en Portugal. Se cita por primera vez para la provincia de Lugo.

\section{Synergus clandestinus Eady, 1952}

Especie inquilina de distribución europea, relativamente poco citada, que se obtiene únicamente de pequeñas bellotas abortadas de distintas especies de Quercus perennifolias o marcescentes. En el área íbero-balear se ha citado en el centro de España y en Cataluña (Nieves-Aldrey y PujadeVillar, 1986; Nieves-Aldrey, 1989; Pujade-Villar, 1992). Se registra por primera vez en Quercus canariensis, cita que supone también la primera de la especie en Andalucía. Adicionalmente se cita por vez primera de la provincia de Toledo.

\section{Synergus hayneanus (Ratzeburg, 1833)}

Se distribuye por Europa central y meridional y el norte de África. Es una especie muy común en el ámbito ibérico, inquilina ligada a agallas de generaciones ágamas de especies de Andricus. Tavares (1920) la cita de Portugal y de Pontevedra y Nieves-Aldrey y Pujade-Villar (1986) la citan de las provincias de Cádiz, Cuenca, Barcelona, Madrid y Salamanca. Se agregan nuevas citas para las provincias de Ciudad Real, Córdoba, Granada y Teruel (primera para Aragón).

\section{Synergus umbraculus (Olivier, 1791)}

Es una de las especies de cinípidos inquilinos más comunes, ampliamente distribuida en toda 
Europa y norte de África. En la Península Ibérica las citas son abundantes; Tavares (1920) recoge las citas de varias localidades de Portugal y del sur de Galicia, en España. Vilarrúbia (1930) y Vilarrúbia y Vilarrúbia (1933) y, posteriormente, Nieves-Aldrey (1986, 1989), Nieves-Aldrey y Pujade-Villar (1986) y Pujade-Villar (1992d) la citan en numerosas localidades del centro, sur y noreste español. Se amplía el área de distribución conocida con nuevas citas de las provincias de La Coruña, Ciudad Real, Córdoba, Málaga, Toledo y Teruel.

\section{Synergus rotundiventris Mayr, 1872}

Especie mal conocida, relativamente poco citada, que se conoce de algunos países de Europa occidental, central y meridional. Las únicas citas ibéricas se deben a Nieves-Aldrey y Pujade-Villar (1987), Nieves-Aldrey (1989) y Pujade-Villar (1992), quienes mencionan la especie en las provincias de Barcelona, Gerona, Guadalajara, Madrid y Salamanca. Se añade la primera cita para la provincia de Ciudad Real.

\section{Synergus gallaepomiformis (Boyer de} Fonscolombe, 1832)

Especie de distribución paleártica. Se encuentra, como inquilina, en más de 40 tipos de agallas de cinípidos (Nieves-Aldrey y Pujade-Villar, en prensa), por lo que es una de las especies más frecuentes y abundantes del género. En la Península Ibérica ha sido citada en Portugal por Tavares (1920) y en España existían citas de las provincias de Barcelona, Cádiz, Gerona, Guadalajara, Guipúzcoa, La Coruña, Lérida, Madrid, Orense, Pontevedra, Salamanca, Segovia y Tarragona (Nieves-Aldrey, 1986, 1989; Nieves-Aldrey y Pujade-Villar, 1987; Pujade-Villar, 1992). Se registra por primera vez para las provincias de León, Logroño, Lugo, Navarra y Palencia

\section{DIPLOLEPIDINI}

\section{Diplolepis eglanteriae (Hartig, 1840)}

Especie paleártica, ampliamente distribuida en Europa, desde Inglaterra a Rusia, llegando al oeste de India. Induce la formación de agallas en hojas de especies de Rosa. En la Península Ibérica las citas son relativamente numerosas; Cogolludo (1921) la cita en Ciudad Real, Madrid y Toledo; Tavares (1927a) la menciona en varias localidades del centro y norte de Portugal y en Galicia, en España; las citas de Nieves-Aldrey $(1984,1989)$ en la provincias de Madrid y Salamanca deben ser atribuidas probablemente a D. centifoliae. Pujade-Villar (1993) la encuentra en distintas provincias catalanas confirmando citas previas de Vilarrúbia (1936). El único adulto que hemos podido identificar con certeza de esta especie proviene de la Selva de Oza (Huesca). Adicionalmente, se han colectado agallas atribuibles a esta especie o a $D$. centifoliae en varias localidades de las provincias de Álava, Cádiz, Cuenca, Gerona, Guadalajara, Huesca, Lugo y Navarra.

\section{Diplolepis centifoliae (Hartig, 1840)}

Distribución europea. Forma agallas aparentemente indistinguibles de las producidas por $D$. eglanteriae. En la Península Ibérica, Nieves-Aldrey (1986) la menciona en Albacete y Guipúzcoa y Pujade-Villar (1993, 1998) en Cataluña y Andorra. En la Sierra de Grazalema se han encontrado recientemente abundantes agallas de esta especie, con la particularidad de estar ya plenamente desarrolladas a finales del mes de marzo, al menos tres meses más temprano de lo que es habitual en el centro y norte España.

\section{Diplolepis nervosa (Curtis, 1838)}

La distribución geográfica de esta especie, que induce la formación de agallas foliares en arbustos del género Rosa, es similar a la de la especie precedente. En la Península Ibérica fue citada primero en Porto y Coimbra (Portugal) (Tavares, 1927a). En España, se conocía únicamente de las provincias de Barcelona y Gerona (Pujade-Villar, 1993). Se han encontrado agallas de esta especie por primera vez en dos localidades de la provincia de Huesca.

Diplolepis rosae (Linnaeus, 1758)

Especie de amplia distribución en la región paleártica. Es una de las pocas especies de cinípidos extensamente citadas en el ámbito íbero-balear, gracias a sus vistosas y comunes agallas. Se conoce en gran parte de Portugal (Tavares, 1930a) y en España se ha citado en numerosas localidades de Galicia, Asturias, Cantabria, las dos Castillas, Madrid, Cataluña y Murcia (Fernández de Gata, 1901; Ventalló, 1905; Lázaro e Ibiza, 1917; Codina, 1920; Cogolludo, 1921; Vilarrúbia, 1930, 1936; Ceballos, 1956; Nieves-Aldrey, 1981; PujadeVillar, 1983; Nieves-Aldrey, 1989). Se amplía la distribución geográfica con nuevas citas en Álava, Albacete, Burgos, Huesca, Lugo, Navarra, Palencia, La Rioja, Soria y Zaragoza.

\section{Diplolepis mayri (Schlechtendal, 1877)}

Al igual que la especie anterior, la distribución de $D$. mayri es muy amplia en toda la región pale- 
ártica. También, como en el caso de D. rosae, las citas de esta especie en la Península Ibérica son relativamente numerosas; Tavares (1927a) la menciona en distintas localidades de Portugal; en España la mayor parte de las citas corresponden a la zona centro, en las provincias de Ávila, Burgos, Guadalajara, Madrid, Salamanca, Segovia y Toledo (Tavares, 1927a; Nieves-Aldrey, 1984, 1989), у a las provincias catalanas (Vilarrúbia y Vilarrúbia, 1933; Vilarrúbia, 1936; Pujade-Villar, 1983). Recientemente se ha citado también en Murcia y Andorra (Pujade-Villar, 1993). Se agregan primeras citas para las provincias de Albacete, Cádiz, Cuenca, Huesca, Jaén, Soria, Zaragoza y Baleares (Mallorca).

\section{CYNIPINI}

\section{Plagiotrochus cardiguensis (Tavares, 1928)}

Esta especie, que induce la formación de pequeñas agallas en los amentos de la encina, se describió sobre material colectado en Cardigos (Portugal) y no volvió a citarse hasta que fue encontrada en la provincia de Madrid (Nieves-Aldrey, 1989) y en Barcelona (Pujade-Villar, 1991). Se añaden citas adicionales de Madrid, Segovia y Salamanca.

Plagiotrochus amenti Kieffer, 1901

Especie nativa del Mediterráneo occidental ligada a Quercus suber, en cuyas ramitas y amentos forma agallas poco conspicuas, que ha sido introducida también en California (Estados Unidos) y en Argentina. En la Península Ibérica se conoce de varias localidades de Portugal (Tavares, 1926) y en España, en Barcelona, Cádiz, Ciudad Real, Gerona, Madrid, Salamanca y Toledo (Nieves-Aldrey, 1982, 1985b, 1989, 1995a; Pujade-Villar, 1991). Se agregan nuevas citas de Jaén y de El Algarve en Portugal.

\section{Plagiotrochus australis (Mayr, 1882)}

Especie del Mediterráneo occidental. En la Península Ibérica es una de las especies más comunes del género, formando agallas en hojas y ramas de encina y coscoja. Tavares (1930a) recopila numerosas citas de Portugal; en España se conocía de Almería, Barcelona, Ciudad Real, Cuenca, Gerona, Lérida, Madrid, Salamanca, Tarragona, Teruel, Toledo y Zaragoza (Nieves-Aldrey, 1982; 1986; 1989; 1995a; Pujade-Villar, 1991). Hay también citas en Andorra (Pujade-Villar, 1996). Su distribución geográfica en España se amplía al agregar nuevas citas para Albacete, Cádiz, Huesca, Jaén, Lugo, Murcia, Soria y Baleares (Mallorca).

\section{Plagiotrochus razeti Barbotin, 1985}

Se conoce únicamente en el sur de Francia y en España, siempre formando agallas en ramitas y estolones de Quercus ilex. En España se ha citado en Madrid (Nieves-Aldrey, 1989, 1995a) y Barcelona (Pujade-Villar, 1991). Se amplía la distribución a Salamanca.

Plagiotrochus panteli Pujade-Villar, 1985

Especie ligada exclusivamente a la coscoja. Presenta una distribución similar a la anterior (Pujade-Villar, 1985a, 1991). Se ha citado en España en distintas localidades de Cataluña (Pujade-Villar, 1991) y se halla también presente en la provincia de Madrid (Nieves-Aldrey, 1995a). Se añaden citas de Almería, Jaén, Málaga, Murcia, Toledo y Valencia.

\section{Plagiotrochus quercusilicis (Fabricius, 1798)}

Especie circunmediterránea, extendida desde el Mediterráneo occidental y norte de África hasta Israel, siguiendo el área de distribución de Quercus ilex y Quercus coccifera, especies botánicas en las que forma sus agallas. En la Península Ibérica está ampliamente extendida y es muy común y abundante; en consecuencia, las citas existentes son numerosas. Tavares (1926) recopila los datos de Portugal, y en España la especie se había citado de las siguientes provincias: Ávila, Baleares, Barcelona, Cáceres, Cuenca, Gerona, Granada, Lérida, Madrid, Salamanca, Sevilla, Tarragona y Toledo (Trotter, 1902; Ventalló, 1905, 1912; Tavares, 1919, 1922, 1926; Cogolludo, 1921; Vilarrúbia, 1936; Ceballos, 1956; NievesAldrey, 1982, 1986, 1989, 1995a; Pujade-Villar, 1991). Se amplía la distribución conocida a las provincias de Álava, Albacete, Almería, Burgos, Cádiz, Castellón, Guadalajara, Jaén, Málaga, Murcia, Soria, Teruel, Valencia, Zamora y Zaragoza.

\section{Plagiotrochus coriaceus (Mayr, 1882)}

Especie mediterránea occidental, presente en Francia, Italia, Argelia y la Península Ibérica. Tavares (1925) citó la especie en Soalheira (Portugal), Nieves-Aldrey (1989) la cita en España en la provincia de Madrid y Pujade-Villar (1986a, 1991, 1996) en Cataluña y Andorra. Se amplía considerablemente su distribución conocida en la Península al agregar nuevas citas para Albacete, Baleares, Cádiz, Castellón, Ciudad Real, Cuenca, Jaén, Toledo, Valencia, Zamora y Zaragoza. 


\section{Plagiotrochus britaniae Barbotin, 1985}

P. britaniae se conoce sólo de Francia, Argelia y España. En el ámbito íbero-balear se había citado en las comunidades de Madrid y Cataluña (NievesAldrey, 1989; Pujade-Villar, 1991). Adicionalmente la citamos de la isla de Mallorca y de Castellón.

\section{Plagiotrochus burnayi Kieffer, 1901}

Se conoce únicamente en la Península Ibérica. Tavares (1926) la menciona como rara en la región de Beira Baixa en Portugal; en España fue primero citada en Salamanca (Nieves-Aldrey, 1982) y posteriormente en Ciudad Real, Madrid y Segovia (NievesAldrey, 1986, 1989), donde es localmente común, así como en la región catalana (Pujade-Villar, 1986a, 1991). También se ha encontrado en Cádiz y Soria.

\section{Plagiotrochus yeusei Barbotin, 1985}

Especie citada exclusivamente en Francia y España. En el ámbito íbero-balear se conocía sólo de Madrid y Barcelona (Nieves-Aldrey, 1989; PujadeVillar, 1991). Se agrega una nueva cita de Zamora.

\section{Callirhytis glandium (Giraud, 1859)}

Especie extendida por Europa central y meridional, con un ciclo biológico heteroécico y las generaciones respectivas asociadas a especies de Quercus de secciones distintas; perennifolias para la generación ágama y caducifolias para la sexuada. En la Península Ibérica ha sido citada por Tavares (1905) en Lousa, São Fiel y Sobral (Portugal) y en España se conoce de Cáceres, Barcelona, Ciudad Real, Lérida, Madrid, Toledo y Salamanca (Nieves-Aldrey, 1982, 1992a; Pujade-Villar, 1991). Se amplían las citas a las provincias de Avila, Cádiz y Guadalajara.

\section{Callirhytis rufescens (Mayr, 1882)}

Especie circunmediterránea, con ciclo biológico similar al de la especie precedente. En la Península Ibérica se ha encontrado hasta ahora sólo en España. Se conoce de Barcelona, Cádiz, Ciudad Real, Gerona, Granada, Madrid, Toledo (PujadeVillar, 1991; Nieves-Aldrey, 1992a). Adicionalmente se han encontrado agallas de la generación sexual, que pudieran ser atribuibles a esta especie en la provincia de Cáceres.

\section{Andricus gallaeurnaeformis (Boyer de} Fonscolombe, 1832)

Especie que se distribuye por Europa central y meridional y Asia Menor. En la Península Ibérica se ha encontrado únicamente en el noreste ibérico, en las provincias de Barcelona, Lérida y Tarragona (Pujade-Villar, 1984, 1985b), donde es una especie relativamente frecuente sobre Quercus humilis. Se añaden diversas citas de la provincia de Gerona.

\section{Andricus curvator Hartig, 1840}

Especie muy común, de amplia distribución en toda Europa, norte de África y Asia Menor. En la Península Ibérica es frecuente y sus citas son relativamente numerosas siempre ligada a especies de Quercus de hoja caduca o marcescente. Tavares (1924) menciona que es una de las especies más habituales en Portugal: se encuentra desde El Algarve a Tras-os-Montes y Alto Minho; Ceballos (1956) recopila las citas de España. Nieves-Aldrey (1983b, 1989) y Pujade-Villar $(1991,1996)$ amplían considerablemente la distribución conocida de la especie en el centro de España y el noreste ibérico. Se cita por vez primera de Álava, Albacete, Cáceres, Cádiz, Cantabria, Granada, Jaén, La Coruña, La Rioja, Málaga, Palencia y Pontevedra.

\section{Andricus pseudoinflator Tavares, 1902}

A. pseudoinflator es una especie Ibérica. En el territorio íbero-balear las citas son relativamente numerosas; Tavares (1919) cita la generación bisexual en varias localidades de Portugal y en España, en Cuenca y Pontevedra. Nieves-Aldrey (1983b, 1989) la cita en Salamanca y Madrid y PujadeVillar (1985b, 1991) en Cataluña. Encontrada ahora también en Albacete, Cantabria, Ciudad Real, Córdoba, Guadalajara, Huesca, Málaga, Teruel y Toledo.

\section{Andricus foecundatrix (Hartig, 1840)}

Especie común, muy ampliamente distribuida en Europa y llegando hasta Irán. En la Península Ibérica se ha citado de distintas localidades de Portugal (Tavares, 1905); en España Cogolludo (1921) la registra de la zona centro y Vilarrúbia $(1930,1936)$ la menciona en Cataluña. Más recientemente se han publicado nuevas datos que amplían su distribución en el centro y noreste de España (Nieves-Aldrey, 1983b, 1989; Pujade-Villar, 1985b, 1991) y en Andorra (Pujade-Villar, 1994). Se menciona por primera vez de Albacete, Ciudad Real, Córdoba, Guadalajara, La Coruña, Lérida, Lugo, Navarra, La Rioja, Soria y Toledo, siempre en especies caducifolias y marcescentes del género Quercus.

\section{Andricus quadrilineatus Hartig, 1840}

Especie extendida preferentemente por Europa septentrional, ligada exclusivamente a especies de 
Quercus de distribución eurosiberiana: $Q$. robur, $Q$. petraea y $Q$. humilis. En la Península Ibérica se conoce sólo en la región noreste y Sistema Central de España (Nieves-Aldrey, 1983b, 1989; PujadeVillar, 1991, 1994). Primera cita para Huesca y Madrid.

\section{Andricus paradoxus (Radoskovsky, 1866)}

Comparte con la especie precedente hábitat y distribución geográfica. En la Península Ibérica las citas son relativamente escasas y sólo de España: Cataluña (Vilarrubia, 1936; Pujade-Villar, 1991) y zona centro (Nieves-Aldrey, 1983b, 1989) exclusivamente sobre $Q$. robur, $Q$. petraea y $Q$. humilis. Se cita por vez primera para Segovia.

\section{Andricus nudus Adler, 1881}

Especie extendida por la mayor parte de Europa. En el área íbero-balear los datos son relativamente escasos; Tavares (1919) la cita en São Fiel (Portugal) y en Cuenca y Pontevedra, en España; Nieves-Aldrey $(1983 b, 1989)$ la menciona en varias provincias de la zona centro y Pujade-Villar (1994) en Andorra. Se añaden nuevas citas para Albacete, Guadalajara y Navarra.

\section{Andricus callidoma (Hartig, 1841)}

El área de distribución de esta especie ocupa gran parte de Europa. En la Península Ibérica se ha citado en Portugal (Tavares, 1905) y en España de Barcelona y Tarragona (Vilarrúbia, 1930, 1936; Pujade-Villar, 1991); Guipúzcoa (Tavares, 1930b); Salamanca, Segovia y Madrid (Nieves-Aldrey, 1983b, 1989). Se aportan primeras citas para Cádiz, Guadalajara y La Rioja.

\section{Andricus quercusramuli (Linnaeus, 1761)}

Especie común, de amplia distribución en Europa, cuya generación sexual induce llamativas agallas en los amentos masculinos de los robles. En el ámbito íbero-balear es frecuente y se ha citado en Portugal (Tavares, 1905, 1916) y en España, en Galicia (Tavares, 1916), en varias provincias del centro (Cogolludo, 1921; Nieves-Aldrey, 1983b, 1989) y en Cataluña y Andorra (Vilarrúbia, 1936; Pujade-Villar, 1991, 1994). Se aportan primeras citas de la especie para las provincias de Cáceres, Cádiz, Córdoba, Jaén, Palencia y Soria.

Andricus floridus Tavares, 1918

Conocida únicamente en la Península Ibérica. Tavares (1918) la describió con material de
Pontevedra. Posteriormente se citó en Salamanca (Nieves-Aldrey, 1983b), así como en las de Barcelona y Tarragona (Pujade-Villar, 1991) y en Andorra (Pujade-Villar, 1994). Se añade la primera cita para Madrid, colectada sobre Quercus petraea.

\section{Andricus quercuscorticis (Linnaeus, 1761)}

Esta especie se encuentra en toda Europa. En la Península Ibérica se ha citado escasamente. Tavares (1905) menciona las dos generaciones en Portugal. En España se ha citado, únicamente la forma ágama, en la zona centro, País Vasco, Cataluña y también en Andorra (Tavares, 1930b; NievesAldrey, 1983b, 1989; Pujade-Villar, 1991, 1994). Se menciona por primera vez de Cantabria, Guadalajara, Navarra y Palencia.

\section{Andricus testaceipes Hartig, 1840}

La distribución geográfica de esta especie es similar a la de la especie afín precedente, con la que comparte parecido habitat. En la Península Ibérica Tavares (1905) la cita en Portugal y en España, Cogolludo (1921) recoge registros de Madrid y Guipúzcoa; Vilarrúbia y Vilarrúbia (1933) y Vilarrúbia (1936) la citan en Barcelona y NievesAldrey (1983b, 1989) y Pujade-Villar (1986a, 1991, 1994) agregan nuevos datos, respectivamente, de las provincias de Salamanca, Madrid y Segovia y, de nuevo, de Barcelona y Andorra. Se añaden nuevas citas para las provincias de Cáceres, Cádiz, Cantabria, Ciudad Real, Guadalajara, León y Lérida.

\section{Andricus quercusradicis (Fabricius, 1798)}

Extendida por toda Europa y norte de África. En el ámbito íbero-balear se ha citado en varias localidades de Portugal (Tavares, 1905) y en España, en Barcelona, Gerona y Tarragona (Vilarrúbia y Vilarrúbia, 1933; Vilarrúbia, 1936; Nieves-Aldrey, 1986; Pujade-Villar, 1991) y en las provincias de Guadalajara, Madrid, Salamanca y Segovia (Nieves-Aldrey, 1983b, 1989), así como en Andorra (Pujade-Villar, 1994). Por primera vez encontrada también en Cáceres, Cantabria, Ciudad Real, La Coruña, León y Soria.

Andricus solitarius (Boyer de Fonscolombe, 1832)

Especie común y ampliamente distribuida en Europa y norte de África, hasta llegar a Irán. La generación ágama se ha citado en la Península Ibérica en distintas localidades de Portugal (Tavares, 1905), en varias provincias del centro, oeste, noroeste y noreste de España (Cogolludo, 
1921; Tavares, 1930b; Vilarrúbia, 1930, 1936; Nieves-Aldrey, 1983b, 1989; Pujade-Villar, 1984, 1985b) y en Andorra (Pujade-Villar, 1997), mientras que la generación bisexual se ha mencionado más raramente (Nieves-Aldrey, 1983b, 1989; Pujade-Villar, 1991). Su distribución conocida se amplia con primeras citas para las provincias de Albacete, Ávila, Cáceres, Ciudad Real, Guadalajara, Huesca, Málaga, Soria y Toledo.

\section{Andricus gemmeus (Giraud, 1859)}

Se conoce en varios países de Europa central y meridional. En la Península Ibérica sólo existen las referencias de Tavares (1905), que la citó en Portugal y de Nieves-Aldrey (1983b) en Salamanca. Adicionalmente se ha encontrado en Cádiz y Jaén, en ambos casos sobre Quercus faginea.

\section{Andricus mayri (Wachtl, 1879)}

La forma nominal de la especie se ha citado en Europa central, mientras que la forma panteli está mucho más extendida por la región circunmediterránea y llega al norte de Africa, Asia Menor e Irán. En la Península Ibérica Tavares $(1905,1922)$ citó la especie en distintas localidades de Portugal y en Cuenca y Galicia en España, Vilarrúbia (1930, 1936) la cita en Cataluña, Nieves-Aldrey (1983b, 1989) en Salamanca y Madrid y Pujade-Villar (1991) nuevamente en el noreste ibérico. Su distribución conocida se amplía notablemente con nuevas citas en las provincias de Albacete, Cáceres, Cádiz, Ciudad Real, Córdoba, Jaén, Málaga, Teruel y Toledo.

\section{Andricus coriarius (Hartig, 1843)}

Se extiende por la mayor parte de Europa central y meridional, el norte de África y Asia Menor. Se halla ampliamente distribuida en la Península Ibérica; Tavares (1931) afirma que es común en todo Portugal; en España se ha citado sobre todo en la zona centro (Cogolludo, 1921; Nieves-Aldrey, 1983b, 1989) y en el noreste ibérico (Vilarrúbia, 1930, 1936; Pujade-Villar, 1984, 1985b) y Andorra (Pujade-Villar, 1997). Se Aportan primeras citas Albacete, Ávila, Cáceres, Cádiz, Ciudad Real, Cuenca, Málaga y Toledo.

\section{Andricus kollari (Hartig, 1843)}

Esta especie, uno de los cinípidos más comunes, se encontraba extendida originalmente en casi todo el sur y centro de Europa, pero ha ido ampliando en tiempos históricos recientes su área de distribución hacia el oeste y norte del continente, siguiendo la creciente introducción de Quercus cerris. Está presente también en el norte de África, Asia Menor y llega hasta Irán. La forma ágama es muy común y se extiende por la mayor parte de la Península Ibérica, aunque falta en las islas Baleares (Tavares, 1931; Nieves-Aldrey, 1983b, 1989; Pujade-Villar, 1984, 1985b, 1991, 1997); las agallas de la forma bisexual, por el contrario, no se han encontrado aún en la Península Ibérica. Su área de distribución conocida en la Península se amplía considerablemente con nuevas citas para las siguientes provincias: Albacete, Ávila, Burgos, Cáceres, Cádiz, Ciudad Real, Córdoba, Cuenca, Granada, Huesca, Jaén, León, Lugo, Málaga, Rioja, Soria, Teruel, Toledo, Zamora y Zaragoza.

\section{Andricus quercustozae (Bosc, 1792)}

Se distribuye por Europa central y meridional, norte de África y Asia Menor. Muy común y extendida en casi toda la Península Ibérica, aunque mucho más rara en el norte y noreste (NievesAldrey, observaciones personales; Cogolludo, 1921; Vilarrúbia, 1930, 1936; Tavares, 1931; Nieves-Aldrey, 1983b, 1986, 1989; Pujade-Villar, 1985b, 1991). Se añaden múltiples citas de localidades de Albacete, Burgos, Cáceres, Cádiz, Ciudad Real, Córdoba, Cuenca, Granada, Huesca, Jaén, La Coruña, León, Lugo, Málaga, Palencia, Sevilla, Soria, Teruel, Toledo y Zamora, provincias todas ellas en las que existían citas aisladas o no se había citado la especie.

Andricus viscosus (Nieves-Aldrey, 1986)

Especie del Mediterráneo occidental. En la Península Ibérica su presencia está confirmada únicamente en el noreste ibérico, donde es una especie relativamente común, sobre todo en Quercus humilis (Codina, 1920; Vilarrúbia, 1930, 1936; NievesAldrey, 1986; Pujade-Villar, 1991, 1994). Se aportan algunas citas adicionales a las ya existentes de las provincias de Barcelona y Gerona.

\section{Andricus pictus (Hartig, 1856)}

Se conoce únicamente en la Península Ibérica, norte de África e Irán. En el ámbito ibérico se describió originalmente, aunque había pasado desapercibida, de la Sierra de Ronda (Pujade-Villar y Bellido, 2000). Posteriormente la especie fue redescubierta y citada de varias localidades de Portugal (Tavares, 1931) y, en España, en distintos puntos de la zona centro (Cogolludo, 1921; Nieves-Aldrey, 1983b, 1989. Se amplía su distribución con nuevas 
citas en las provincias de Cádiz, Ciudad Real, Cuenca y Málaga.

\section{Andricus grossulariae Giraud, 1859}

Especie de distribución circunmediterránea, ligada específicamente a Quercus cerris y Quercus suber. En la Península Ibérica Tavares (1905) la cita en varias localidades de Portugal y también en España (Tavares, 1925); Nieves-Aldrey (1982) la menciona en Salamanca y Pujade-Villar (1986a), en Barcelona y Gerona. Adicionalmente se ha encontrado, siempre asociada al alcornoque, en distintas localidades de Cáceres, Cádiz, Ciudad Real y Madrid.

\section{Andricus burgundus Giraud, 1859}

Especie del Mediterráneo occidental que llega por el norte hasta Austria. En el ámbito ibérico se ha citado, al igual que la especie anterior siempre sobre Quercus suber, en Portugal (Tavares, 1905) y en España, únicamente en Pontevedra (Tavares, 1918), Salamanca (Nieves-Aldrey, 1982), Barcelona y Gerona (Pujade-Villar, 1985b, 1986a, 1991). Se aportan nuevas citas para Cáceres, Ciudad Real, Gerona, Madrid y Toledo.

Andricus niger Tavares, 1902

Especie ibérica muy afín a la precedente. En Portugal se ha citado en Setúbal, Cintra y región de São Fiel (Tavares, 1916) y en España se conoce en Pontevedra, Salamanca y Madrid (Tavares, 1916; Nieves-Aldrey, 1982, 1989). Se señala su presencia en La Coruña, Lugo y Toledo.

\section{Andricus glandulae (Hartig, 1840)}

Especie de distribución europea. La presencia de esta especie en la Península Ibérica, al menos respecto a la generación ágama, consta únicamente por citas de las agallas. Las agallas de la generación ágama fueron citadas por primera vez en el ámbito ibérico en Braga y Geres (Portugal) por Tavares (1905); más tarde el mismo autor las menciona también en España (Tavares, 1921) y, más recientemente, se han encontrado en Andorra (Pujade-Villar, 1997). Las agallas de la generación sexual se han citado en Barcelona, sobre Quercus petraea (Pujade-Villar, 1986a). Las agallas de la generación ágama de esta especie encontradas sobre Quercus petraea en Somosierra representan una nueva e interesante cita para la provincia de Madrid.

Neuroterus anthracinus (Curtis, 1838)

Especie de distribución paleártica occidental, común en Europa y también en la Península
Ibérica. Tavares (1902a, 1922) la menciona en distintas localidades de Portugal. En España se ha citado principalmente en Galicia, zona centro y Cataluña (Tavares, 1922; Ceballos, 1956; NievesAldrey, 1983b, 1989; Pujade-Villar, 1991). Ampliamos notablemente su distribución peninsular con primeras citas en las siguientes provincias: Álava, Albacete, Cádiz, Córdoba, Granada, Huesca, La Coruña, León, Lérida, Lugo, Málaga, Navarra, Soria y Zaragoza.

\section{Neuroterus saliens (Kollar, 1857)}

Especie circunmediterránea, extendida también en parte del centro de Europa siguiendo las áreas de distribución de Qercus suber y $Q$. cerris. En la Península Ibérica existen citas procedentes de numerosas localidades de Portugal (Tavares, 1928) y en España se conoce en Galicia (Tavares, 1928), Cataluña (Vilarrúbia, 1956; Pujade-Villar, 1991), Salamanca y Madrid (Nieves-Aldrey, 1983a, 1989). Se añaden nuevas citas para Cádiz y Toledo.

\section{Neuroterus aprilinus (Giraud, 1859)}

Es común en casi toda Europa y llega hasta el norte de África y Asia Menor. En la Península Ibérica se ha citado en distintas localidades de Portugal y en España, en Galicia y Cataluña (Tavares, 1928; Vilarrúbia, 1956); Nieves-Aldrey (1983a, 1989) la cita en Salamanca y Madrid y Pujade-Villar (1991, 1994, 1997) en varias localidades catalanas y Andorra. Adicionalmente se menciona por primera vez en las provincias de Albacete, Ávila, Cáceres y Toledo.

\section{Neuroterus tricolor (Hartig, 1841)}

Ampliamente distribuida en la mayor parte de Europa, norte de África y Asia menor. En la Península Ibérica es localmente común; Tavares (1928) y Vilarrúbia (1956) recopilan las citas de la especie en el ámbito ibérico mencionándola en distintas localidades de Portugal y de las provincias españolas de Asturias, Barcelona, Cuenca, Gerona, Guipúzcoa, La Coruña, Madrid, Orense, Pontevedra y Salamanca. Nieves-Aldrey (1983a, 1989) vuelve a citarla en Salamanca y Madrid y Pujade-Villar (1991, 1996) la menciona en nuevas localidades de la región catalana y Andorra. Se amplían las citas conocidas al encontrarla también también en quejigares y robledales de las provincias de Cáceres, Cádiz, Ciudad Real, Córdoba, Guadalajara y Málaga. 


\section{Neuroterus quercusbaccarum (Linnaeus, 1758)}

Es una de las especies de cinípidos más comunes en la región paleártica occidental y más concretamente en la Península Ibérica. Tavares (1928) y Vilarrúbia (1956) citan la especie en numerosas localidades de Portugal y España, sobre todo en Galicia, la zona centro y Cataluña; más tarde, Nieves-Aldrey (1983a, 1986, 1989) y Pujade-Villar (1991, 1996) añaden más datos procedentes de la zona centro de España y Cataluña. Se amplía considerablemente su distribución en España aportando nuevas citas para las provincias de Álava, Albacete, Ávila, Cáceres, Cádiz, Ciudad Real, Córdoba, Granada, Jaén, León, Málaga, Navarra, Palencia, Soria, Teruel, Zamora y Zaragoza.

\section{Neuroterus numismalis (Geoffroy, 1785)}

La distribución de esta especie es paleártica occidental. En la Península Ibérica se ha citado en distintas localidades de Portugal (Tavares, 1928) y en España principalmente en la mitad norte: Galicia, País Vasco, Castilla, Madrid y Cataluña (Cogolludo, 1921; Tavares, 1928; Vilarrúbia, 1956; Nieves-Aldrey, 1983a, 1986, 1989; Pujade-Villar, 1991, 1996). Se añaden por primera vez citas para Cádiz, Córdoba, Granada, Huesca, Jaén, La Rioja, Lérida, Lugo, Málaga, Navarra, Soria y Zaragoza.

\section{Neuroterus albipes (Schenck, 1863)}

$\mathrm{Al}$ igual que en la especie precedente su distribución es paleártica occidental. Tavares (1928) y Vilarrúbia (1956) recopilan las citas en la Península Ibérica, referidas fundamentalmente a distintas regiones de Portugal y, en España, a Galicia y Cataluña. Nieves-Aldrey (1983a, 1989) aporta datos de Salamanca y Madrid y Pujade-Villar $(1991,1996)$ la menciona en numerosas localidades de las provincias catalanas y de Andorra. Al igual que las especies precedentes, se ha encontrado en amplias áreas de la Península donde no estaba citada, mencionándose por vez primera en las provincias de Álava, Albacete, Burgos, Cádiz, Córdoba, Granada, Huesca, Málaga, Navarra, La Rioja, Soria, Teruel y Zaragoza.

\section{Cynips quercusfolii Linnaeus, 1758}

Especie distribuida en toda Europa, probablemente con la excepción de las áreas más meridionales. En la Península Ibérica está ausente de Portugal, mientras que en España la especie es localmente frecuente en el noreste ibérico (PujadeVillar, 1991, 1996) y muy rara en el Sistema Central, ligada a los enclaves relictos de $Q$. petraea en Somosierra y Ayllón (Nieves-Aldrey, 1989). Se aporta una cita adicional de la provincia de Gerona.

Cynips quercus (Geoffroy, 1785)

El área de distribución de esta especie cubre gran parte de Europa central y meridional, norte de Africa y Asia Menor y llega a Irán. En el ámbito íbero-balear es una especie común, asociada a las áreas de distribución de Quercus pyrenaica, $Q$. faginea, $Q$. humilis $Q$. canariensis y $Q$. lusitanica en las que induce la formación de agallas. La generación ágama se ha citado en numerosas localidades de Portugal (Tavares, 1928) y en España, en Galicia (Tavares, 1928), Toledo, Ciudad Real y Madrid (Cogolludo, 1921), en múltiples localidades de Salamanca, Madrid y Guadalajara (NievesAldrey, 1983a, 1989) y del noreste ibérico, así como en Cataluña y Andorra (Vilarrúbia, 1930, 1936; Pujade-Villar, 1984, 1991, 1996). Se señalan nuevas citas para las provincias de Albacete, Cádiz, Ciudad Real, Granada, León, Málaga, Palencia, Soria y Zaragoza.

\section{Cynips divisa Hartig, 1840}

Especie distribuida por la mayor parte de Europa y el norte de África. La forma ágama se ha citado en distintas localidades del norte de Portugal (Tavares, 1928) y en España, en Galicia, Asturias y varias provincias del centro y del noreste ibérico (Cogolludo, 1921; Tavares, 1928; Nieves-Aldrey, 1983a, 1989; Pujade-Villar, 1991). Se cita por primera vez de las provincias de Cáceres, Palencia y Soria.

\section{Cynips disticha Hartig, 1840}

Especie con similar distribución geográfica a la de la especie precedente, si bien un poco más amplia, ya que llega por el este hasta Irán. La forma ágama ha sido citada en Portugal (Tavares, 1928) y en España, en distintas localidades de Galicia, Castilla, Madrid y Cataluña (Tavares, 1928; Nieves-Aldrey, 1983a, 1989; Pujade-Villar, 1991). Encontrada ahora también en quejigos y robles de las provincias de Cádiz, Ciudad Real, Huesca, Lugo, Navarra y Soria.

\section{Trigonaspis synaspis (Hartig, 1841)}

Especie ampliamente distribuida en Europa, norte de África y Asia Menor. En la Península Ibérica se ha citado en Portugal (Tavares, 1927a); en España existen citas dudosas de Laguna (1880) y García Maceira (1911) en Cogolludo (1921); más recientemente se ha mencionado en distintas locali- 
dades de Salamanca y Madrid, Ciudad Real y Cádiz (Nieves-Aldrey, 1983a, 1989, 1990) y también en Cataluña (Pujade-Villar, 1991). A partir de agallas de la generación sexual atribuibles a esta especie se cita aquí de Guadalajara y La Rioja.

Trigonaspis mendesi Tavares, 1902

Especie Ibérica. Se ha citado en varias localidades de Portugal (Tavares, 1927a) y en España se conoce en Córdoba, Ciudad Real, Cuenca, Guadalajara, Madrid, Salamanca y Zamora (Nieves-Aldrey, 1982, 1989, 1990). Se agregan las primeras citas para Jaén.

Biorhiza pallida (Olivier, 1791)

Es una especie muy común que se encuentra en toda Europa, norte de África y Asia Menor. Muy frecuente y ampliamente citada en casi toda la Península Ibérica; en Portugal son muy numerosas las citas en la mayor parte del territorio, casi todas correspondientes a la generación bisexual (Tavares, 1928); en España se encuentran citas antiguas de agallas correspondientes a dicha generación en las provincias de Cáceres, Madrid, Orense y Pontevedra (Cogolludo, 1921; Tavares, 1928) y en las provincias catalanas (Codina, 1928, Vilarrúbia, 1930, 1936). Más recientemente se han ampliado considerablemente las citas en el centro de España y el noreste ibérico (Nieves-Aldrey, 1983a, 1989; Pujade-Villar, 1991, 1997). Se incrementa notablemente su distribución conocida en España con primeras ciatas para Asturias, Cádiz, Cantabria, Granada, Huesca, Jaén, León, Lugo, Navarra, Palencia, Soria, Toledo, Vizcaya y Zaragoza.

\section{Comentarios y Discusión}

Las 140 especies de cinípidos catalogadas en el área íbero-balear representan un 50\% de las especies europeas y entre un 10 y un $14 \%$ de la fauna mundial del grupo (Nieves-Aldrey, en prensa). En este trabajo se listan 88 especies, representando un $63 \%$ del total ibérico, aportando para todas ellas nuevos datos de distribución geográfica y biología en el ámbito íbero-balear. La amplitud de la lista, del área geográfica estudiada y la extensión temporal del estudio singularizan este trabajo del que, en el caso de los cinípidos, se puede afirmar que no existen precedentes de estudios similares o comparables en nuestro país.

Con objeto de ilustrar la mejora que supone este trabajo sobre la faunística y corología de los cinípi- dos ibéricos, de ha efectuado la recopilación del número de especies de cinípidos citadas por provincia en España, comparándolo con el de nuevas citas aportadas en el mismo. El resultado se refleja gráficamente en la figura 1 . Se producen aportaciones nuevas para un total de 40 de las 48 provincias españolas del ámbito íbero-balear. Los porcentajes de incremento de citas nuevas son significativos para la mayor parte de ellas, oscilando entre un incremento mínimo de 3\% hasta un máximo del $2700 \%$ para la provincia de Jaén. La media de incremento se cifra en un 447 por ciento. Cabe destacar los casos de las provincias de Lugo y Navarra (14 especies nuevas frente a 1 previamente citada), Huesca (17 fente a 3), Teruel (14 y 4), Jaén (27 frente a 1), Málaga (22 frente a ninguna), Cádiz (32 y 9), Soria (19 y 0) o Albacete (19 y 1). Únicamente en el caso de cinco provincias: Orense, Guipúzcua, Barcelona, Tarragona, y Sevilla no se ha incrementado la lista de especies, mientras que tan sólo en el caso de tres provincias de España: Alicante, Badajoz y Huelva no se ha citado aún ninguna especie de cinípido.

Es interesante observar también, en la misma gráfica de la fígura 1 el número de especies de cinípidos citadas por provincia en España. Atendiendo a estos datos la provincia con mayor número de especies de cinípidos citadas es Madrid, seguida de Salamanca y Barcelona. Las 99 especies de la Comunidad de Madrid representan el $71 \%$ del total de los cinípidos del área íbero-balear, cifra muy alta si tenemos en cuenta que de las mencionadas 140 especies ibéricas, al menos 16 se consideran raras o de presencia o status dudoso. Las cifras de las provincias mencionadas, todos ellas intensamente prospectadas, representan una riqueza cercana a la real; por el contrario, para gran parte de las otras provincias, los números son probablemente inferiores a las cifras reales, dada la insuficiencia de los muestreos efectuados. La riqueza de especies de cinípidos de una determinada área geográfica está correlacionada con la presencia en la misma de sus plantas hospedadoras, y especialmente con la existencia de especies de Quercus, plantas a las que están asociadas de modo específico hasta un $70 \%$ de las especies de cinípidos (Nieves-Aldrey, en prensa). Teniendo en cuenta esta premisa, la riqueza potencial de cinípidos en muchas provincias españolas será muy superior a la que reflejan las cifras de la figura 1. En particular cabe esperar incrementos significativos, a medida que aumente el esfuerzo de muestreo, en la mayor parte de las provincias andaluzas, especialmente en Huelva, Córdoba y Sevilla; en las extremeñas, en muchas de 


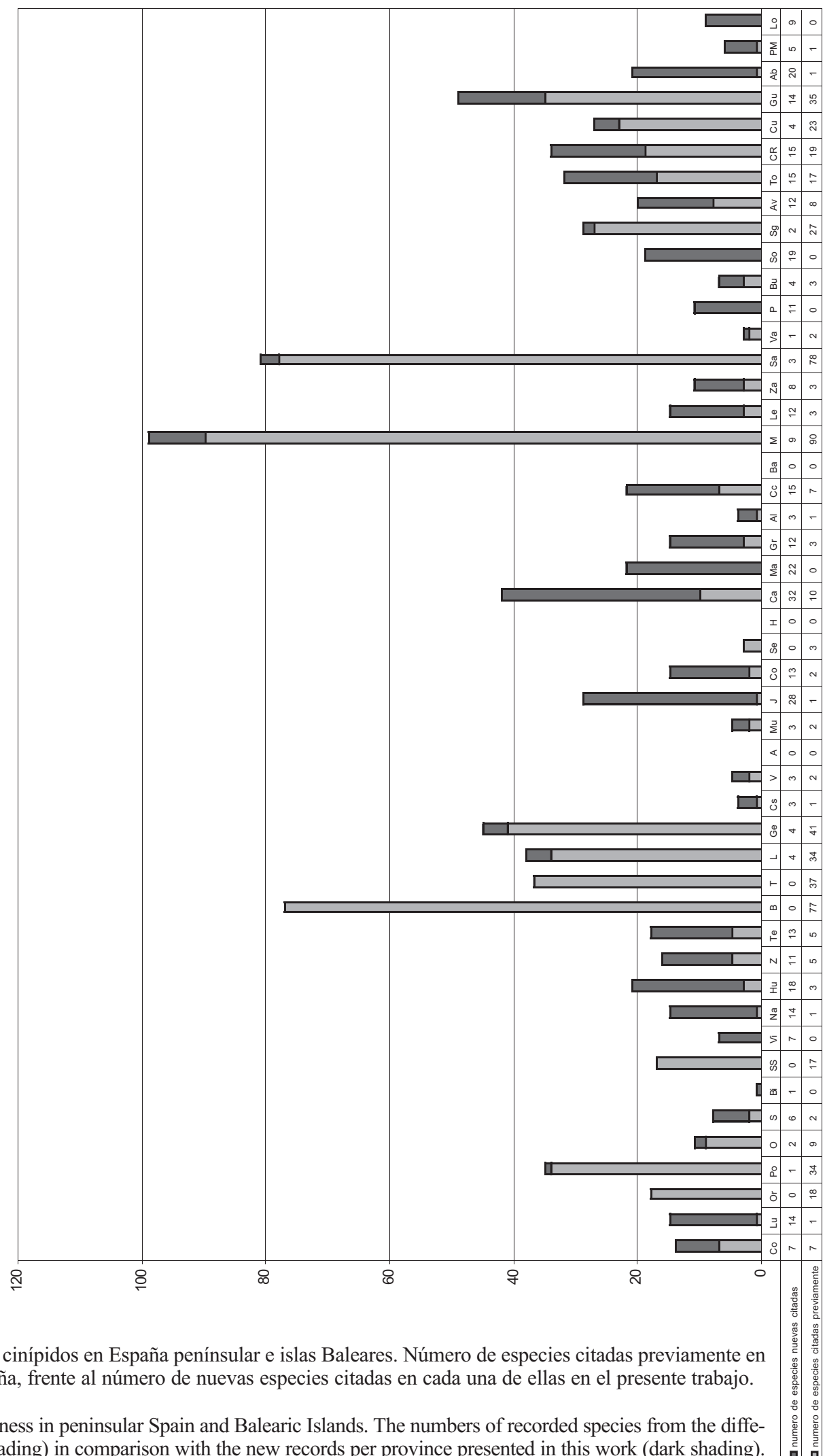
Fig. 1.- Provincial cynipid richness in peninsular Spain and Balearic Islands. The numbers of recorded species from the diffe-
rent provinces of Spain (light shading) in comparison with the new records per province presented in this work (dark shading). 


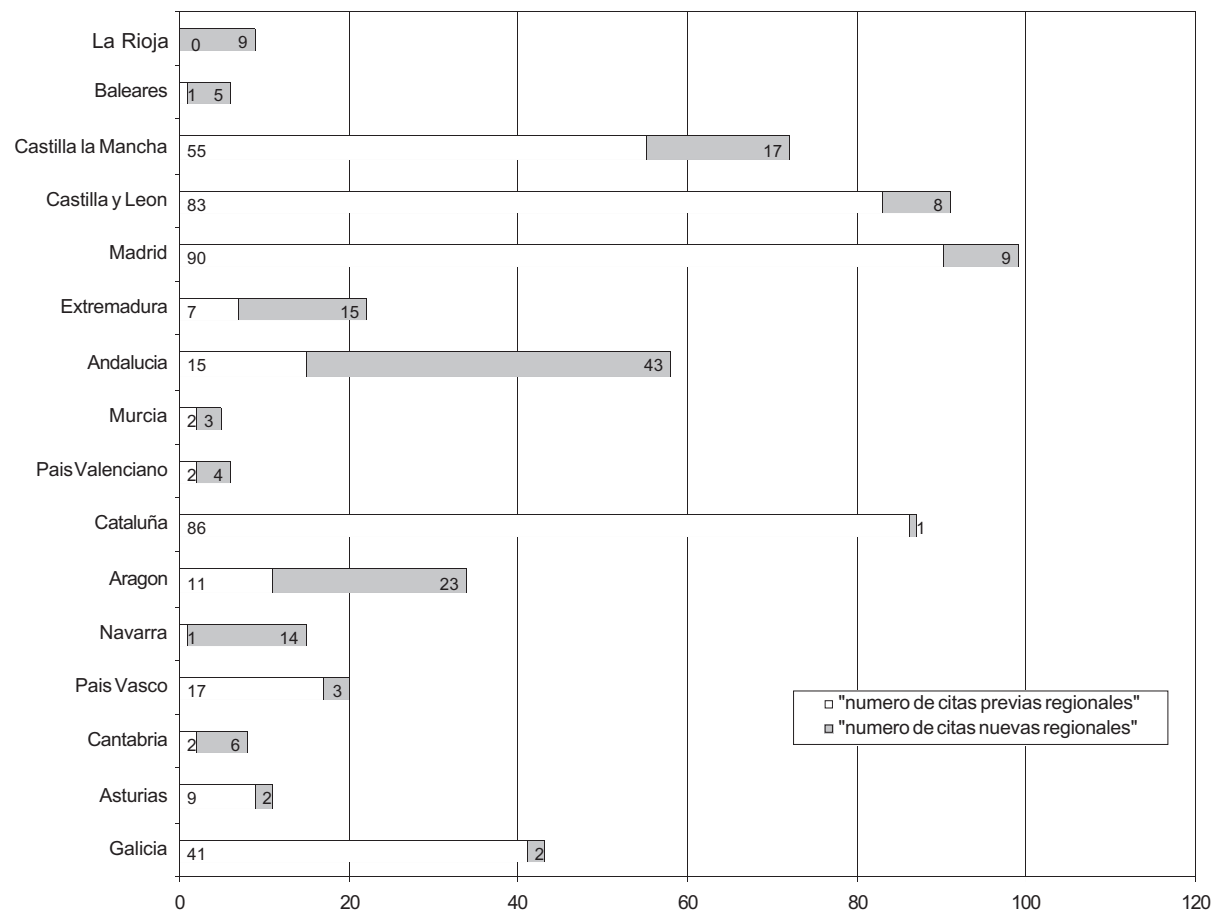

Fig. 2.- Riqueza regional de cinípidos en España penínsular e islas Baleares. Número de citas previas regionales comparadas con el número de nuevas citas por región aportadas en el presente trabajo.

Fig. 2.- Regional cynipid records in Spain. Numbers of previously recorded species per region (light shading) compared with the numbers of new records per region from this work (dark shading).

las dos Castillas, en las aragonesas y en Navarra y La Rioja.

En la figura 2 se ilustran los datos de riqueza regional de cinípidos en España. Para cada caso se indica el número de citas previas regionales existentes frente al número de citas nuevas aportadas en el presente trabajo. Se puede apreciar que los datos recogidos en este trabajo suponen incrementos sustanciales sobre las cifras previas conocidas, especialmente en los casos de Andalucía, Aragón, Navarra, La Rioja, Extremadura y Castilla la Mancha, hasta ahora escasamente prospectadas. Madrid, Castilla y León y Cataluña se significan como las regiones con mayor riqueza de cinípidos, con arreglo a los datos actuales. Sin embargo estas tres regiones son también, con diferencia, las que han sido muestreadas con mayor intensidad y es previsible que, a medida que se incremente el esfuerzo de muestreo en las primeras, algunas muestren cifras comparables de riqueza.

A pesar de este déficit de muestreo de muchas regiones de la Península, al que se ha aludido, no es probable que se produzcan para el conjunto de cini- pidofauna ibérica adiciones significativas a la lista de especies. La única tribu en la que cabe esperar, quizás, nuevos hallazgos es Aylacini. Los representantes de esta tribu primitiva de cinípidos inducen agallas, muchas veces inconspicuas, en plantas herbáceas de distintas familias botánicas y su muestreo es, con frecuencia, difícil y aleatorio. Predecimos futuras novedades en la descripción de alguna posible especie nueva, o la aparición en Iberia de alguna especie presente en áreas geográficas vecinas, especialmente entre las ligadas a plantas papaveráceas, labiadas y asteráceas. En las especies vinculadas a fagáceas del género Quercus esperamos pocas novedadas, con la posible excepción de la fauna asociada a Quercus canariensis y Quercus lusitani$c a$, aún insuficientemente prospectada.

En este trabajo aportamos por primera vez en España datos de cinípidos asociados a estas dos especies de Quercus, mencionadas anteriormente, endémicas del sur de la Península Ibérica y norte de Africa. En concreto para $Q$. lusitanica (=fruticosa) se citan las siguientes especies: Andricus callidoma, Andricus gemmeus, Andricus kollari, Andricus 
mayri panteli, Andricus quercusramuli, Andricus quercustozae, Neuroterus albipes, Neuroterus anthracinus y Trigonaspis synaspis. Por lo que respecta a $Q$. canariensis se aporta una lista de 18 especies: Synergus clandestinus, Synergus hayneanus, Andricus coriarius, Andricus curvator, Andricus gemmeus, Andricus kollari, Andricus mayri panteli, Andricus quercusramuli, Andricus quercustozae, Andricus testaceipes, Neuroterus albipes, Neuroterus anthracinus, Neuroterus numismalis, Neuroterus quercusbaccarum, Cynips disticha, Cynips quercus, y Biorhiza pallida.

\section{Referencias}

Ceballos, G., 1956. Catálogo de los himenópteros de España. Consejo Superior de Investigaciones Científicas. Instituto Español de Entomología. Madrid. 554 pp.

CoDINA, A., 1920. Recull de zoocecidies catalanes. Butlletí de la Institució Catalana d'Historia Natural, 20: 178-187.

CodinA, A., 1928. Un nuevo cynipido de Balenya. Butlletí de la Institució Catalana d'Historia Natural, 8: 130-131.

Cogolludo, J., 1921. Contribución al conocimiento de las zoocecidias de España. Trabajos del Museo Nacional de Ciencias Naturales de Madrid, Serie Botánica, 16: 1-117.

FERNÁNDEZ DE GATA, M., 1901. Nuevos estudios sobre las agallas. Boletín de la Sociedad Española de Historia Natural, 1: 194-199, 231-331, 345-353, 385-402.

GARCÍA MACEIRA, A., 1911. Las agallas foliares de los robles. Publicación Oficial del Ministerio de Fomento. Madrid. $3+33$ pp.

LAGUNA, M., 1880. Nota sobre las agallas encontradas en El Escorial. Actas de la Real Sociedad Española de Historia Natural, 9: 10-11.

LÁzAro E IBIZA, B., 1917. Noticias de algunas agallas de España. Asociación Española para el Progreso de las Ciencias, Congreso de Valladolid, Sección 4, Ciencias Naturales: 5-55.

Nieves-Aldrey, J.L., 1981. Datos sobre Diplolepis rosae (L.) (Hym., Cynipidae) y su fauna de himenópteros parásitos en Salamanca. Boletín de la Asociación Española de Entomología, [1980], 4: 107-113.

Nieves-Aldrey, J.L., 1982. Contribución al conocimiento de los cinípidos gallícolas (Hym., Cynipidae) de la encina y el alcornoque en la provincia de Salamanca. Boletín de la Asociación Española de Entomología, [1981], 5: 59-74.

Nieves-Aldrey, J.L., 1983a. Contribución al conocimiento de los cinípidos gallícolas (Hym., Cynipidae) de los robles y quejigos. II. Género Neuroterus Htg., Cynips L., Trigonaspis Htg., Biorhiza West. y Callirhytis Foerst. Boletín de la Asociación Española de Entomología, [1981], 6: 343-367.

Nieves-Aldrey, J.L., 1983b. Contribución al conocimiento de los cinípidos gallícolas (Hym., Cynipidae) de los robles y quejigos. III: Andricus Hartig (Hym., Cynipidae). Boletín de la Asociación Española de Entomología, 7: 115-145.

Nieves-Aldrey, J.L, 1984. Contribución al conocimiento de la fauna de himenópteros inquilinos y parásitos en las agallas de Diplolepis mayri (Schlechtendal) y Diplolepis eglanteriae (Hartig) (Hym., Cynipidae). Graellsia, [1983]. 39: 93-102.

Nieves-AldRey, J.L., 1985a. Notas sobre los Aylaxini (Hym., Cynipidae, Cynipinae) de la Península Ibérica, con descripción de una nueva especie de Isocolus. Eos, [1984], 60: 235-250.

Nieves-Aldrey, J.L., 1985b. Biología de Plagiotrochus amenti Tav. (Hym., Cynipidae) cinípido cecidógeno nocivo para el alcornoque. Boletim da Sociedade Portuguesa de Entomologia (Actas do III Congreso Ibérico de Entomologia, Lisboa), Suppl. 1: 105-116.

Nieves-Aldrey, J.L., 1985c. Nuevos Aylaxini (Hym., Cynipidae) para la Península Ibérica con descripción de una nueva especie de Aylax Htg. Boletim da Sociedade Portuguesa de Entomologia (Actas do III Congreso Ibérico de Entomologia, Lisboa), Suppl. 1: 117-128.

NieVES-AldREY, J.L., 1986. La colección de cinípidos gallícolas (Hym., Cynipidae, Cynipinae) del Instituto Español de Entomología. Graellsia, [1985], 41: 113124

Nieves-AldREY, J.L., 1988. Descripción de una nueva especie de Isocolus Förster con notas de otras especies de Aylaxini nuevas para la Península Ibérica (Hym., Cynipidae). Eos, 64(1): 221-227.

NieVES-AldREY, J.L., 1989. Los cinípidos gallícolas e inquilinos de la Sierra de Guadarrama y zonas adyacentes (Hym., Cynipidae). Eos, [1988], 64(2): 125 163.

Nieves-AldRey, J.L., 1990. Sobre las especies europeas del género Trigonaspis Htg., con descripción de una nueva especie de España (Hym., Cynipidae). Eos, [1989], 65(2): 91-108.

Nieves-AldRey, J.L., 1992a. Revisión de las especies europeas del género Callirhytis (Hymenoptera, Cynipidae). Graellsia, 48: 171-183.

NieVES-AldREY, J.L., 1994. Revisión of C.G.Thomson's nominal species of Aylacini (Hymenoptera: Cynipidae). Entomologica Scandinavica, 25: 151158.

NiEveS-AldREY, J.L., 1995a. Abundancia, diversidad y dinámica temporal de cinípidos en dos hábitas del centro de España (Hymenoptera, Cynipidae). En: Comité Organizador del VI Congreso Ibérico de 
Entomología (eds.). Avances en Entomología Ibérica. Madrid: 113-136.

Nieves-Aldrey, J. L., en prensa. Hymenoptera, Cynipidae. En: Fauna Ibérica., vol. 16. Ramos, M.A. et al. (Eds). Museo Nacional de Ciencias Naturales. CSIC. Madrid.

Nieves-Aldrey, J.L. y Pujade-Villar, J., 1986. Sobre las especies ibéricas de la sección I (Mayr, 1872) del género Synergus Htg. (Hymenoptera, Cynipidae, Cynipinae). Eos, [1985], 61: 214-237.

Nieves-Aldrey, J.L. y Pujade-Villar, J., 1987. Sobre las especies ibéricas de la sección II (Mayr 1872) del género Synergus Hartig, con descripción de una especie nueva (Hym., Cynipidae, Cynipinae). Eos, [1986], 62: 137-165.

Pujade-VILlaR, J., 1983. Algunas consideraciones sobre Diplolepis rosae y D. mayri (Schlechtendal) en Cataluña (Hymenoptera, Cynipoidea, Cynipidae, Cynipinae). Actas del Primer Congreso Ibérico de Entomología, León, 2: 613-622.

Pujade-Villar, J., 1984. Algunes dades sobre les deformacions de plantes produïdes per Cinípids cecidògens (Hymenoptera, Cynipinae), trobades a Catalunya. Folia Botànica Miscelanea, 4: 59-69.

Pujade-VILlar, J., 1985a. Sobre Plagiotrochus pantel n. sp. (Hymenoptera, Cynipidae). Publicaciones del Departamento de Zoología, Universidad de Barcelona, 11: 55-60.

Pujade-VILlar, J., 1985b. Sobre alguns cinípids cecidògens trobats en els roures de Sant Llorenç del Munt i Serra de l'Obac. I Col.loqui de Naturalistes vallesans. Annals del Centre Vallesà d'estudis dels Ecosistemes mediterranis, 1: 87-92.

Pujade-Villar, J., 1986a. Noves espècies de cinípids cecidògens per a Catalunya i per a la Peninsula Ibèrica. Sessió d'Entomologia de la Institució Catalana d'Història Natural-Societat Catalana de Lepidopterologia, [1985] 4:147-154.

Pujade-Villar, J., 1986b. Sobre Pediaspis Tischbein, 1852, nuevo género de cinípido para la Península Ibérica (Hym., Cynipidae, Cynipinae). Publicaciones del Departamento de Zoología, Universidad de Barcelona, 12: 83-86.

Pujade-VILlar, J., 1991. Contribució al coneixement dels cinipids cecidógens dels arbres $i$ arbusts de Catalunya dels cinípids associats a aquests $i$ dels seus paràsits. Tesis doctoral. Universidad de Barcelona. Barcelona. 1128 pp.

Pujade-Villar, J., 1992. Sobre Synergus ilicinus (Barbotin, 1972) n.comb. y otras especies de Synergus Htg. en el Nordeste de la Península Ibérica (Hym., Cynipidae, Synergini). Boletín de la Asociación española de Entomología, 16: 129148.

Pujade-Villar, J., 1993. Revisió de les espècies del gènere Diplolepis de l'Europa centro-occidental
(Hym., Cynipidae) amb una especial atenció a la Península Ibérica. Historia Animalium, 2: 57-76.

Pujade-Villar, J., 1994. Formes cinipo-cecidògenes detectades, o que poden detectar-se, en les flors i els fruits de les fagàcies a Andorra (Hym.: Cynipidae: Cynipinae). Annals Institute Estudes. Andorrans. Centre de Barcelona, [1992]: 137-162.

Pujade-Villar, J., 1996. Zoocecids presents a les fulles de fagàcies andorranes, causats per cinípids (Hym., Cynipidae). Annals de l'Institut d'Estudis Andorrans (Centre de Barcelona), 1994: 79-102.

Pujade-Villar, J., 1997. Malformacions produïdes per cinípids als borrons de fagàcies detectades a Andorra. Annals de l'Institut d'Estudis Andorrans (Centre de Barcelona), 1995: 13-39

Pujade-Villar, J., 1998. Els cinípids cecidògens presents a Andorra que no es troben en fagàcies (Hym.: Cyn.: Aylacini, Rhoditini). Annals de l'Institut d'Estudis Andorrans (Centre de Barcelona), 1996: 91-98.

Pujade-Villar, J. y Nieves-Aldrey, J.L., 1990. Revisión de las especies europeas del género Saphonecrus D.T. y K., 1910 (Hymenoptera, Cynipidae). Butlletí de la Institució Catalana d'Historia Natural (serie de Zoologia), 58: 45-55.

Pujade-Villar, J. y Nieves-Aldrey, J.L., 1993. Revisión de las especies europeas del género Ceroptres Htg. 1840 (Hymenoptera, Cynipidae). Boletín de la Asociación Española de Entomología, 17(2): 49-63.

Pujade-VILlar, J. y Ros-FarRé, P., 1998. Inqilinos y parasitoides de las agallas del género Plagiotrochus Mayr colectada en el Nordeste de la Península Ibérica. Boletín de la Asociación española de Entomología, 22 (1-2): 115-143.

Pujade-Villar, J. y Bellido, D., 2000. Sobre las especies de cinípidos (Hymenoptera, Cynipidae) descritas por Hartig en la Sierra de Ronda. Boletín de la Asociación Española de Entomología, 24 (1-2): 260262.

TAVARES, J. DA S., 1902a. As zoocecidias portuguesas, enumeração das especies ate agora encontradas em Portugal e descripção de dezanove ainda nao estudadas. Annaes de Sciencias Naturaes, Porto, [1900], 7 : 17-106.

TAVARES, J. DA S., 1905. Synopse das zoocecidias portuguesas. Brotéria, 4: $14+1-123$.

TAVARES, J. DA S., 1916. Espécies e variedades novas de Cynípides e Cecidomyias da Peninsula Iberica e descripção de algunas ja conhecidas. Brotéria, Série Zoologica, 14: 65-136.

Tavares, J. DA S., 1918. Espécies novas de Cynípides e Cecidomyias da Peninsula Iberica e descripção de algunas ja conhecidas. Segunda série. Brotéria, Série Zoologica, 16: 130-141. 
Tavares, J. DA S., 1919. Espécies novas de Cynípides e Cecidomyias da Peninsula Iberica e descripção de algunas ja conhecidas. Segunda série (Cont.). Brotéria, Série Zoologica, 17: 5-101.

TAVAres, J. DA S., 1920. Synergariae ou les Cynipides commensaux d'autres Cynipides dans la Péninsule Ibérique. Memoires de la Société Portugaise des Sciences Naturelles, 4: 2 + 1-77.

TAVARES, J. DA S., 1921. Cecidias novas para Espanha. Primeira série. Brotéria, Série Zoologica, 19: 30-68.

TAvares, J. DA S., 1922. Espécies novas de Cynípides e Cecidomyias da Peninsula Ibérica e descripção de algunas ja conhecidas. Quarta série. Brotéria, Série Zoologica, 20: 97-155.

Tavares, J. DA S., 1924. Espécies novas de Cynípides e Cecidomyias da Peninsula Iberica e descripção de algumas ja conhecidas. Quinta série. Brotéria, Série Zoologica, 21: 5-48.

TAVARES, J. DA S., 1925. Importancia da Cecidologia da Peninsula Ibérica. Brotéria, Série Zoologica, 22: 8498.

Tavares, J. DA S., 1926. Os Cynípides da Peninsula Ibérica. Brotéria, Série Zoologica, 23: 16-78.

Tavares, J. DA S., 1927a. Os Cynípides da Peninsula Ibérica. Brotéria, Série Zoologica, 23: 47-140.

TAvares, J. DA S., 1927b. O género Timaspis Mayr (Cynipidae) na Península Ibérica. Comunicação feita ao Congresso luso-espanhol de Cádiz. Asociación Española para el Progreso de las Ciencias, Madrid: 93-101.

Tavares, J. DA S., 1928. Os Cynípides da Peninsula Ibérica. Brotéria, Série Zoologica, 26: 11-152.

Tavares, J. DA S., 1930a. Os Cynípides da Peninsula Ibérica. Brotéria, Série Zoologica, 26: 25-53.

TAVArES, J. DA S., 1930b. Cecídias de Zumárraga (Guipúzcoa, España). Brotéria, Série Zoologica, 26: 113-119.

Tavares, J. DA S., 1931. Os Cynípides da Peninsula Ibérica. Brotéria, Série Zoologica, 26: 5-100.

Trotter, T. , 1902. Elenco di galle racolte in Ispagna. Marcellia, 1(4): 122-126.
Ventalló, D., 1905. Algunas Zoo-cecidias de Tarrassa. Butlletí de la Institució Catalana d'Historia Natural, 1905: 65 .

Ventalló, D., 1912. Notes cecidològiques. Butlletí de la Institució Catalana d'Historia Natural, 1912: 164.

VILARRÚBIA, L., 1930. Cynipocecidies Vigatanes. Butlletí de la Institució Catalana d'Historia Natural, 19: $28-32$

VILARRÚBIA, A., 1936. Les zoocecidies de les plantes de Catalunya. Trevalls del Museo de Ciencias Naturales de Barcelona, 11(10): 1-106.

VilarrúBiA, A., 1956. Zoocecidias de la Península Ibérica. Fasc. 1. Cynipidae (G. Neuroterus). Trabajos del Museo de Zoología del Museo de Ciencias Naturales de Barcelona, Nueva Serie. Zoología, 2(1): $7+1-31$.

VilarRúBIA, A. y VILARRÚBIA, L., 1933. Recull de zoocedies vigatanes. Butlletí de la Institució Catalana d'Historia Natural, 33(4-5): 232-240. 


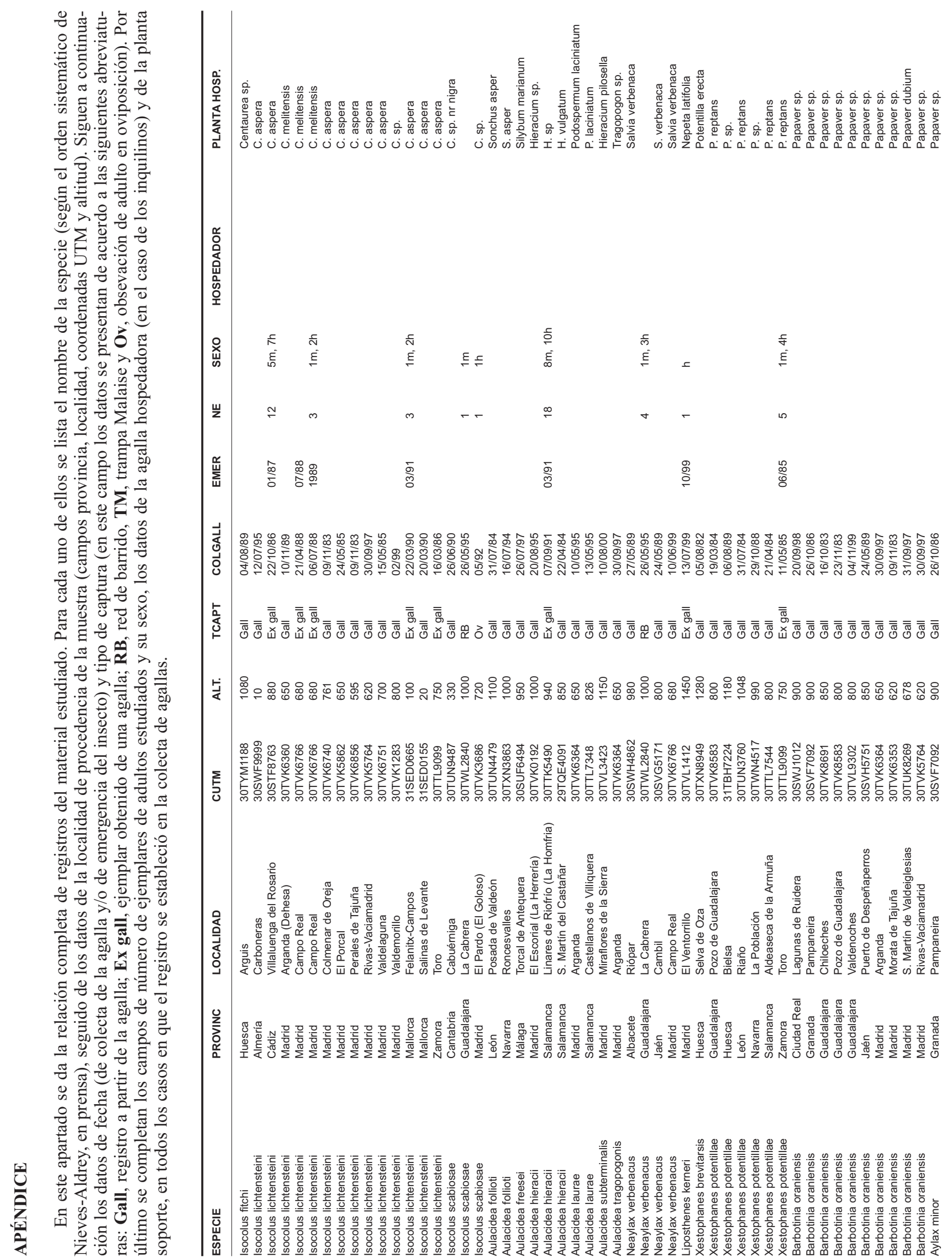




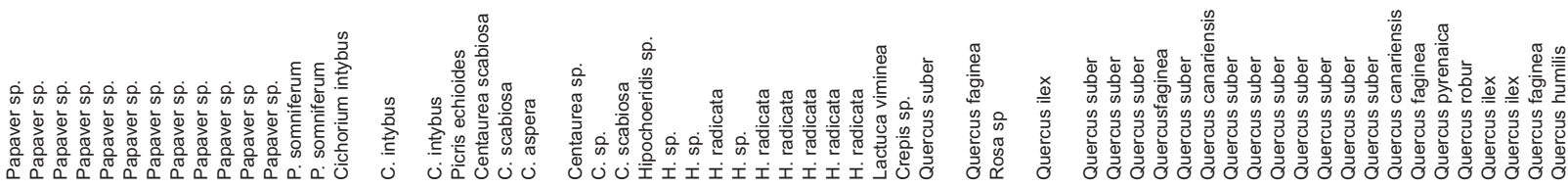

\begin{tabular}{|c|c|c|c|c|c|c|c|}
\hline & & & & & & 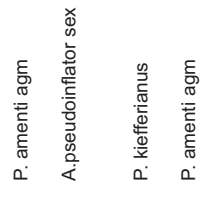 & \\
\hline $\begin{array}{l}\text { ल. } \\
\underline{E}\end{array}$ & $=$ & 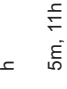 & $=$ & 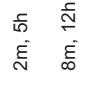 & & 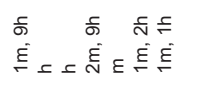 & $=$ \\
\hline 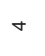 & - & $-\stackrel{\varphi}{-}$ & 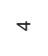 & $\wedge$ i & $\stackrel{\circ}{\sim}$ & 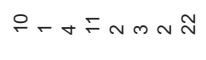 & $\infty$ \\
\hline 商 & 量 & 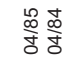 & 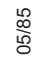 & 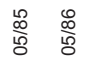 & 帝 & 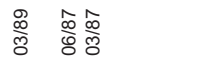 & $\frac{\bar{\delta}}{\overline{0}}$ \\
\hline
\end{tabular}

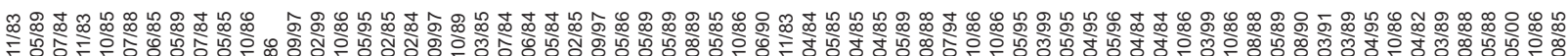

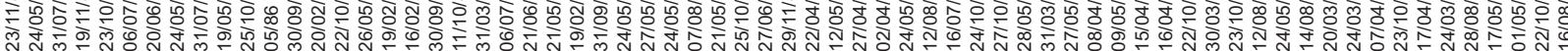

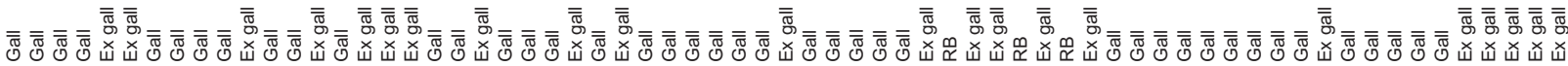

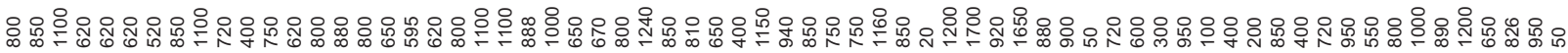

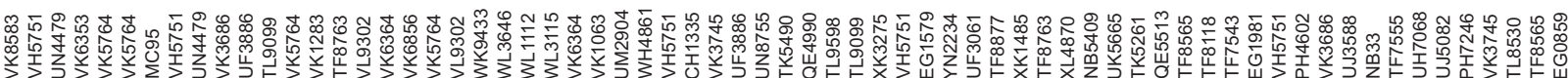

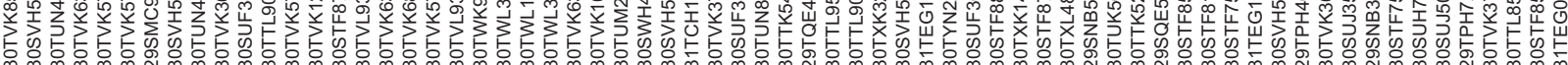

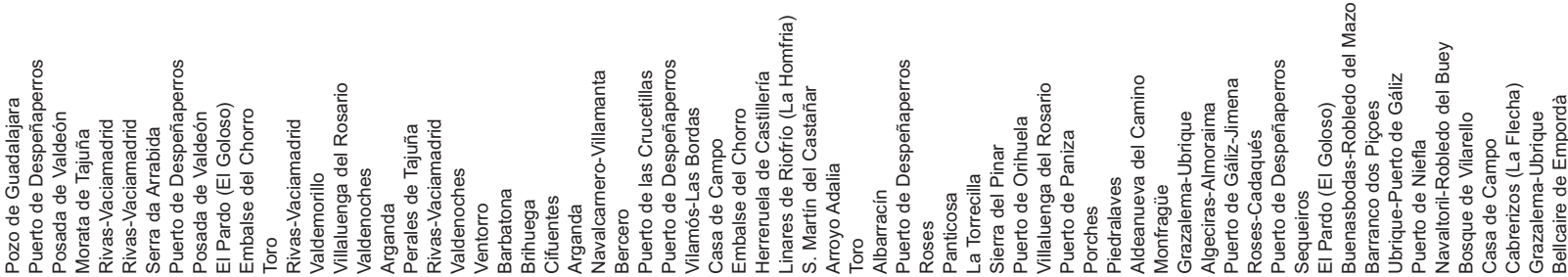

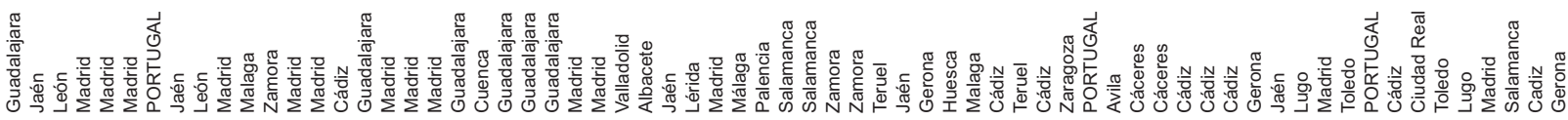

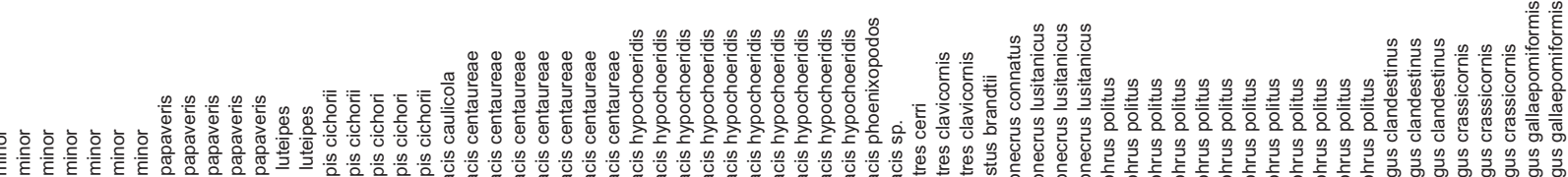

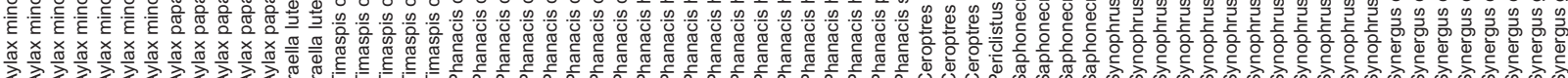



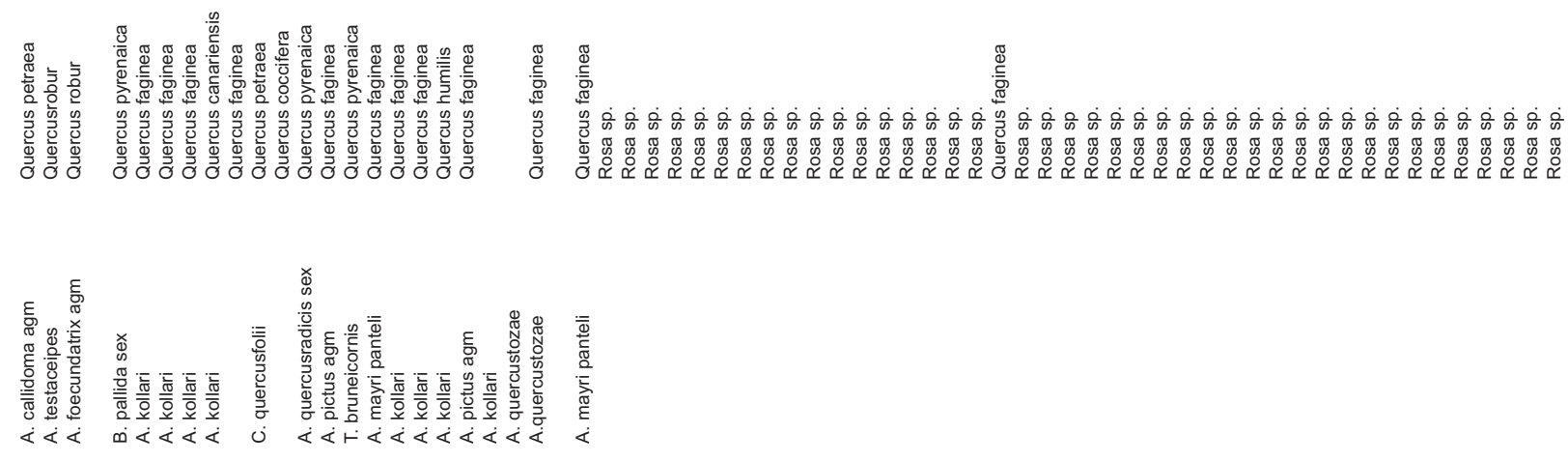

ร ᄃ

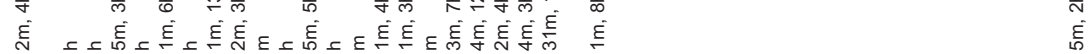

ம

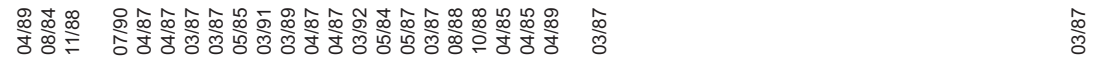

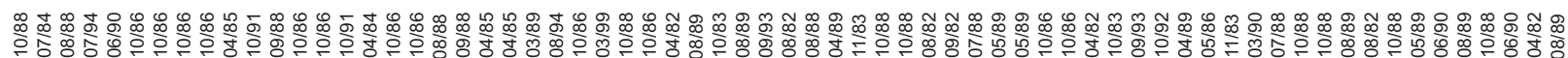

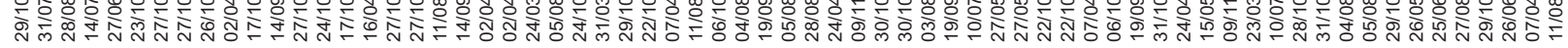

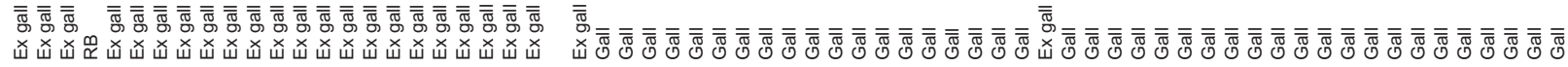

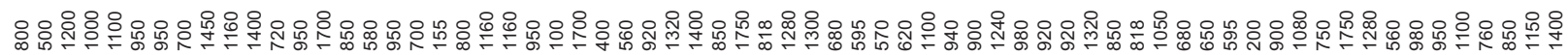

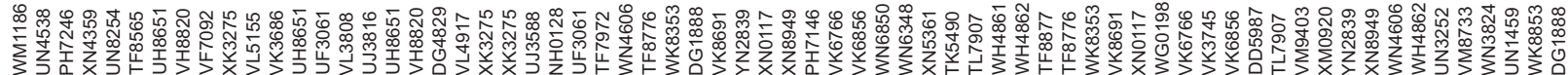

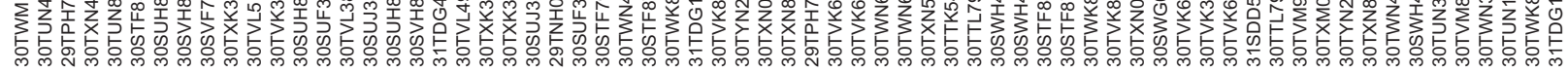

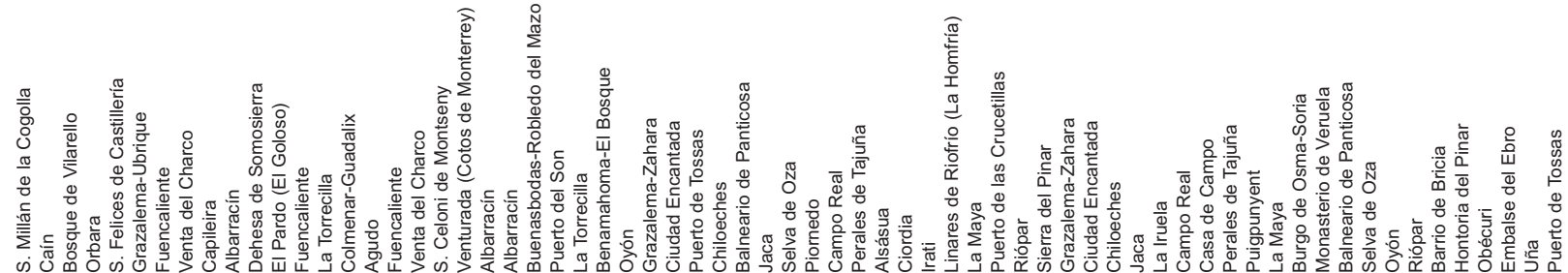

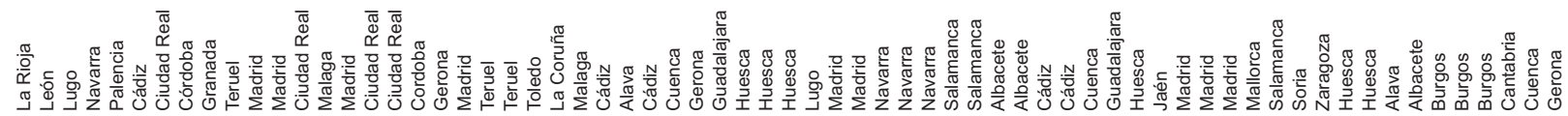

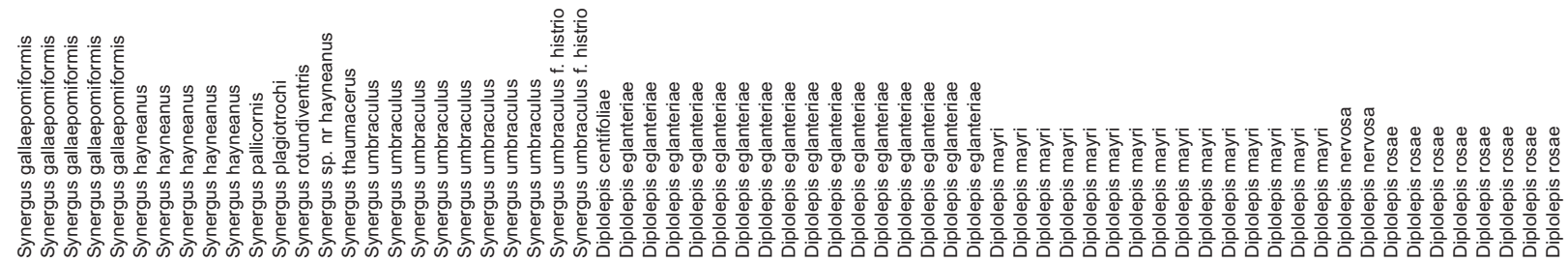




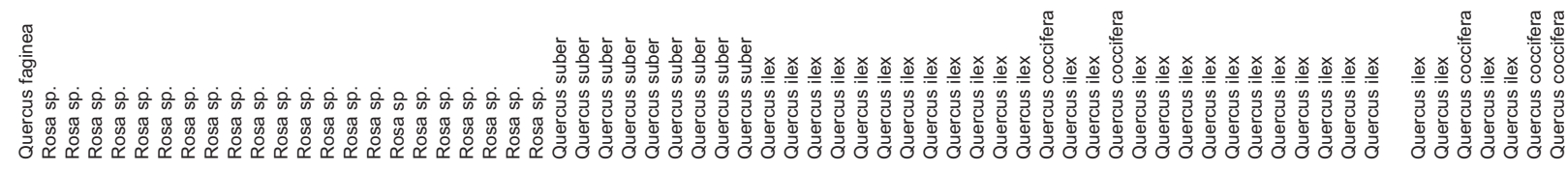

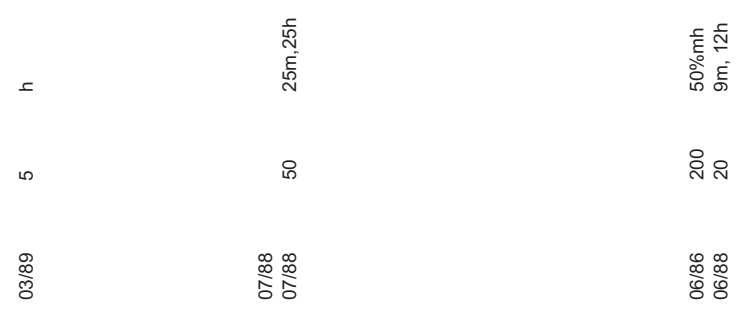

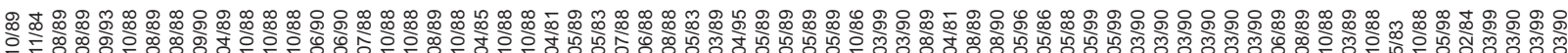

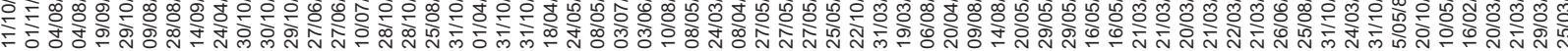

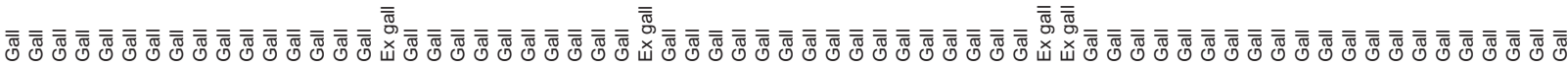

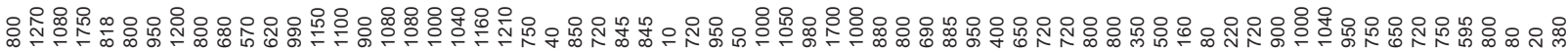

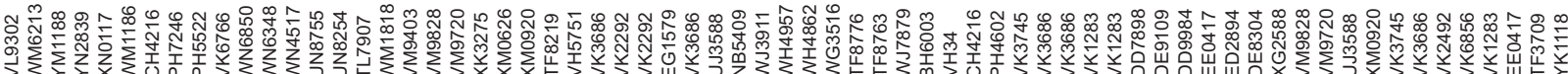

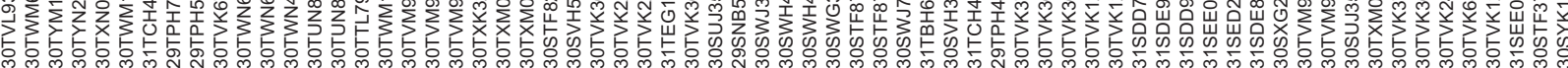

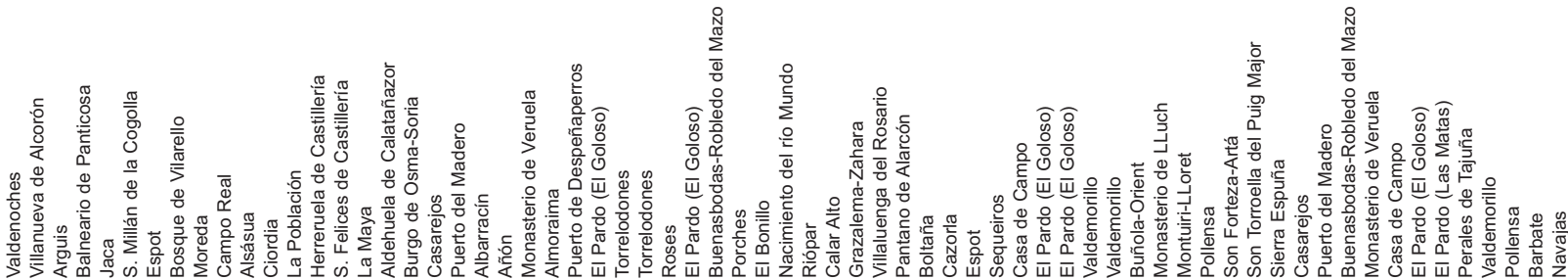

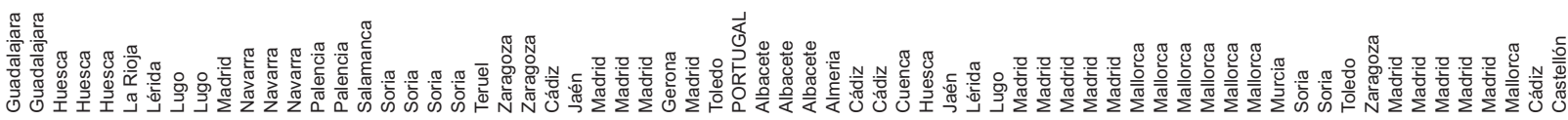




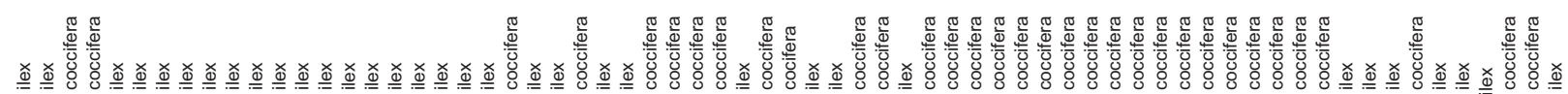

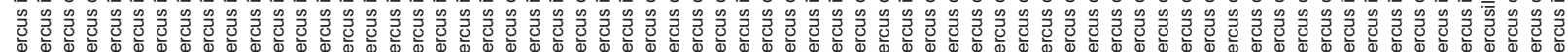

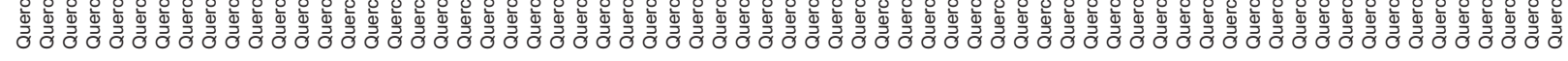

\begin{tabular}{|c|c|c|c|c|}
\hline$\underline{\mathbb{g}}$ & 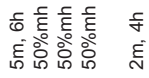 & s & $\begin{array}{l}\stackrel{\Sigma}{N} \\
\underset{N}{\tilde{N}}\end{array}$ & $\begin{array}{l}\text { ह } \\
\underline{m}\end{array}$ \\
\hline ما & $=$ 吾员员 & ల్ల & $\nabla$ & $\sigma$ \\
\hline & 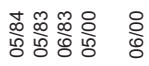 & $\frac{8}{8}$ & $\begin{array}{l}\stackrel{8}{8} \\
\text { 岁 }\end{array}$ & 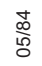 \\
\hline
\end{tabular}

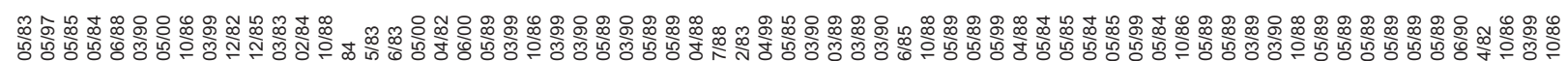

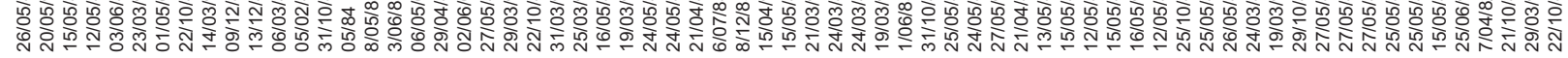

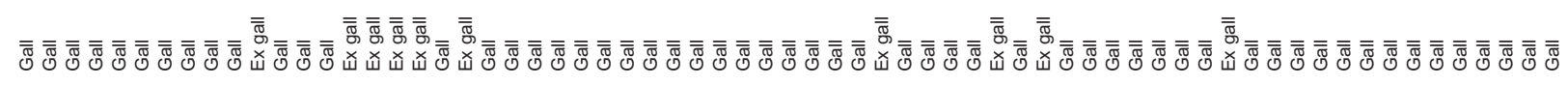

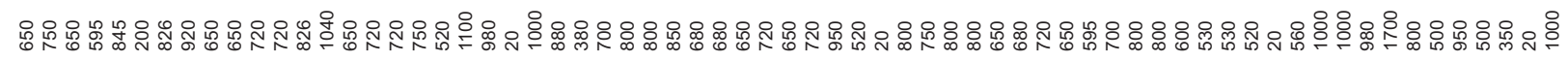

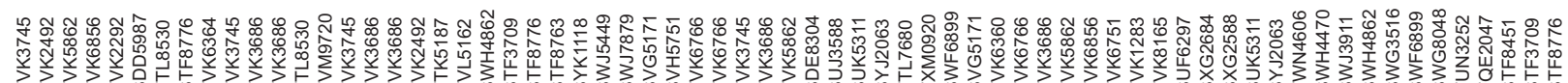

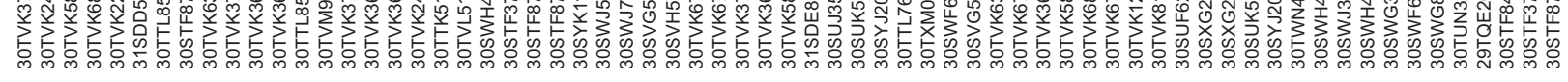

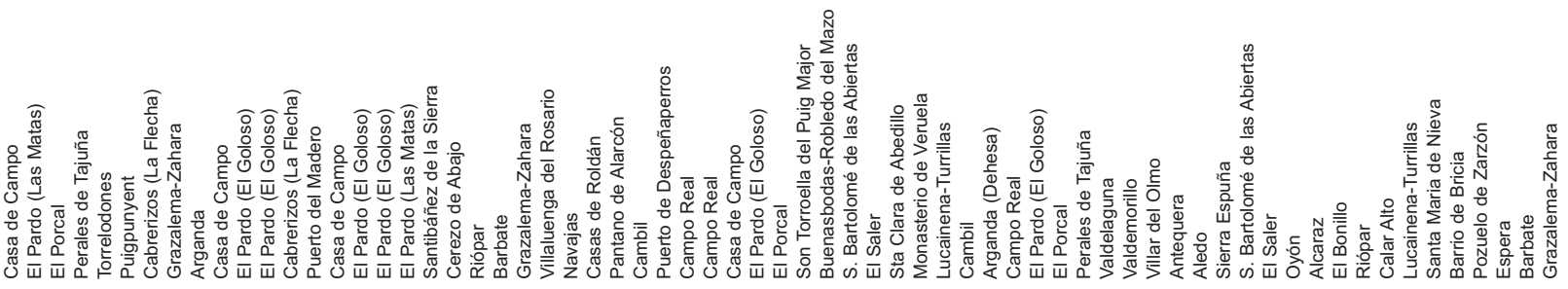

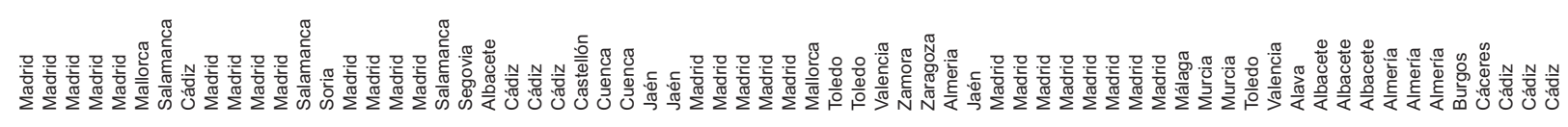

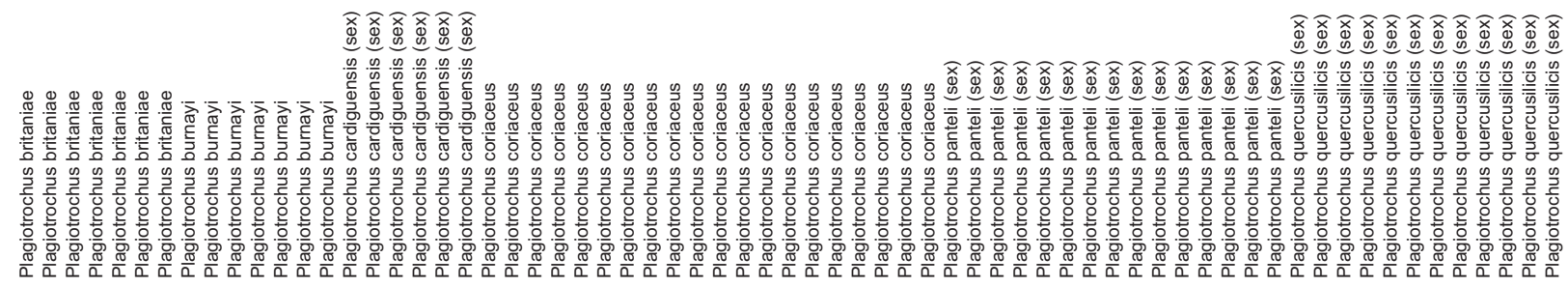




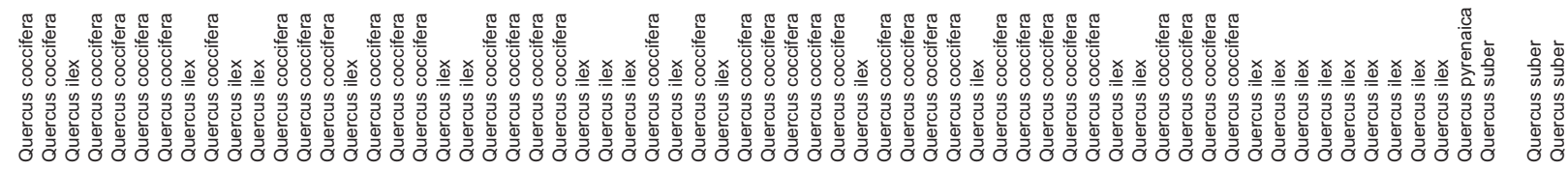

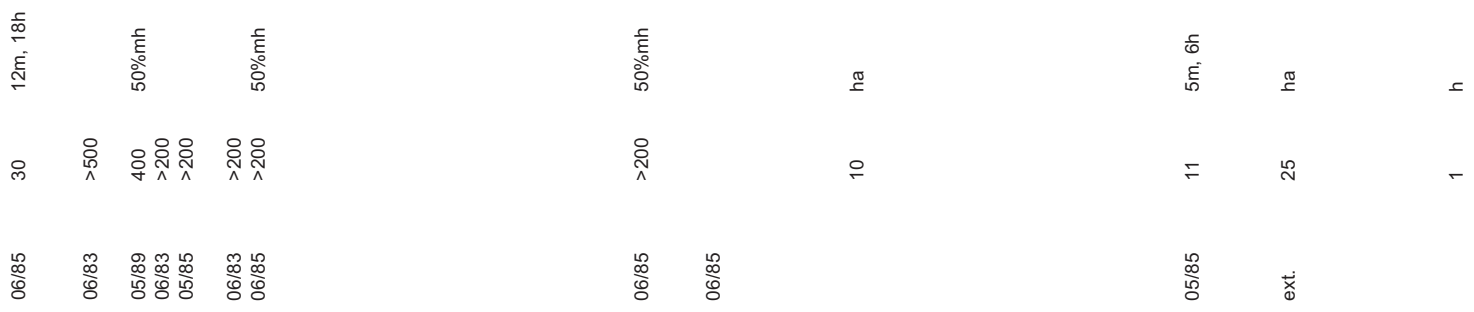

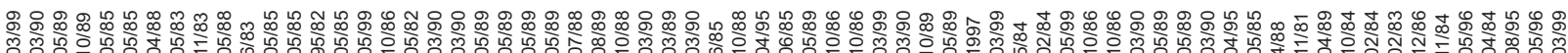

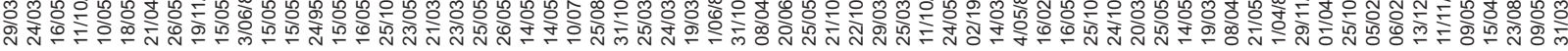

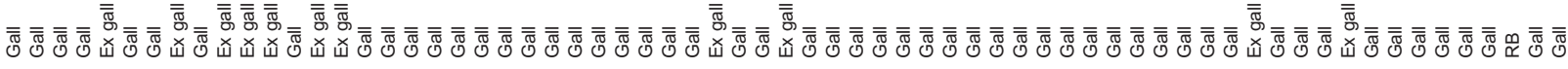

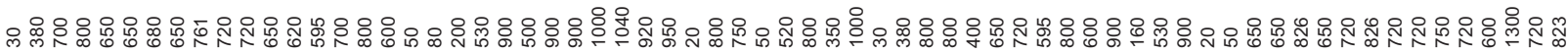

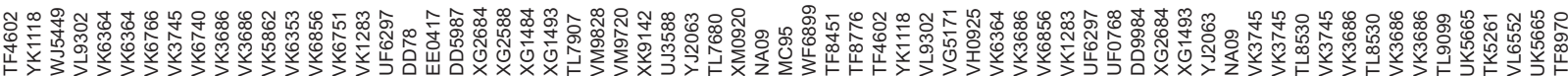

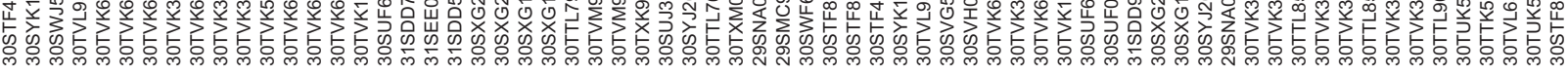

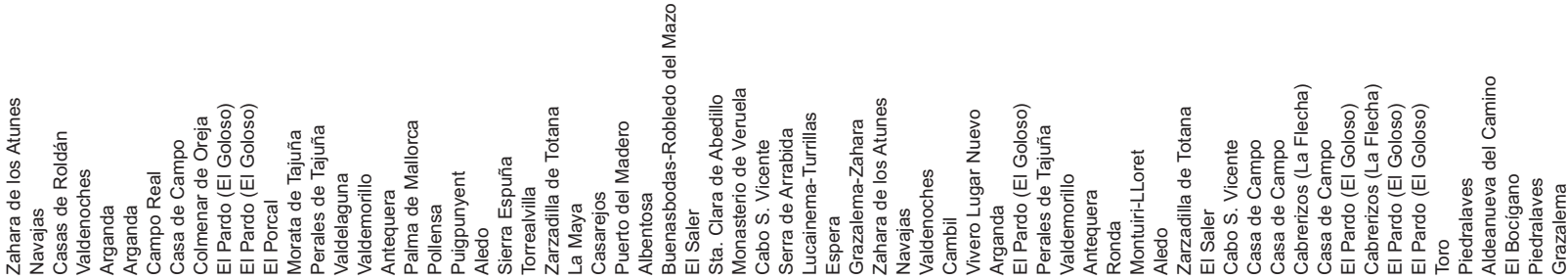

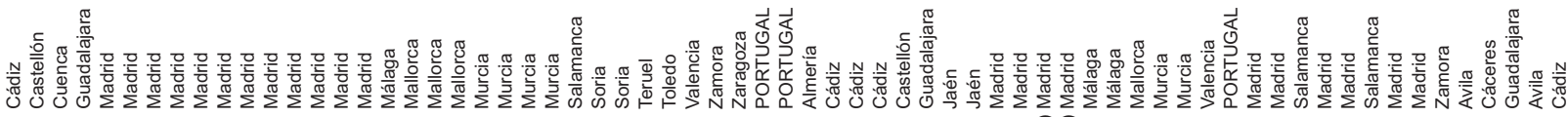

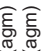

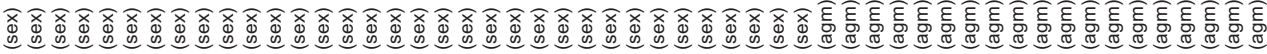

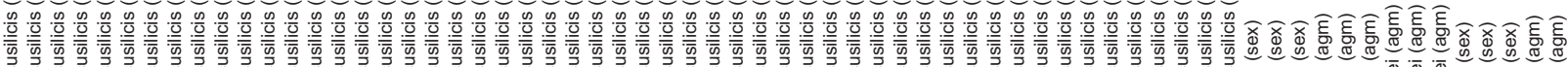

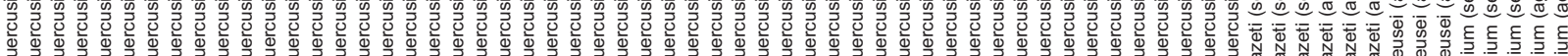

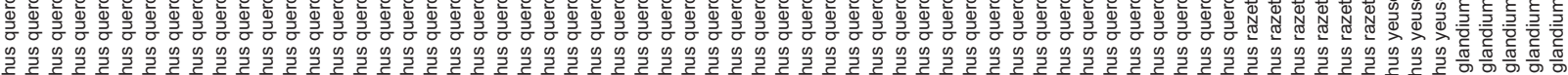

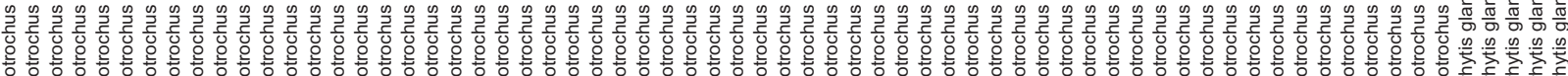

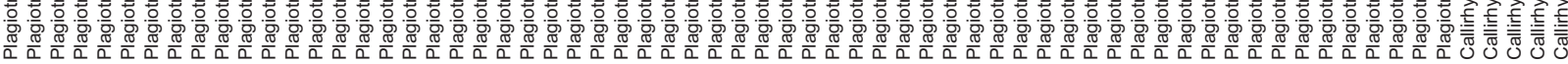




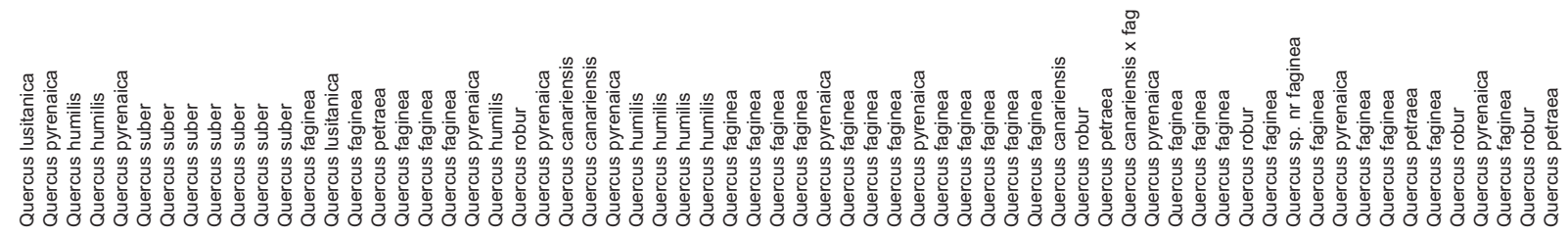

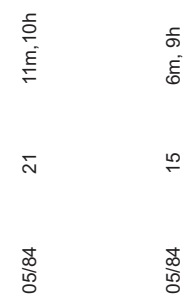

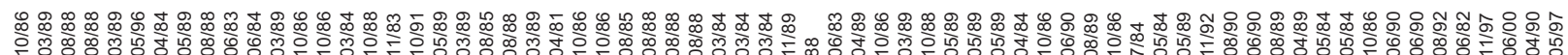

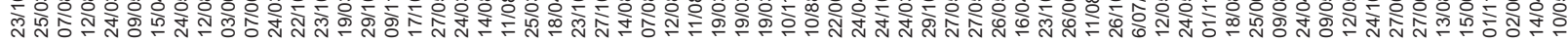

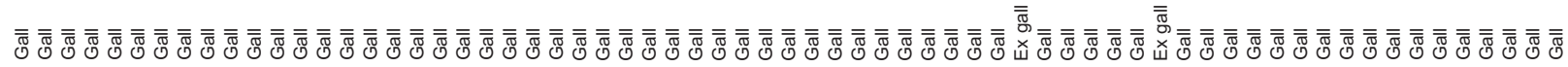

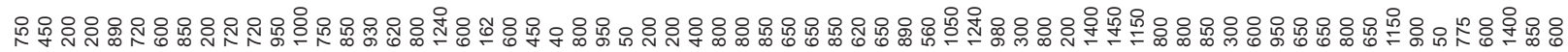

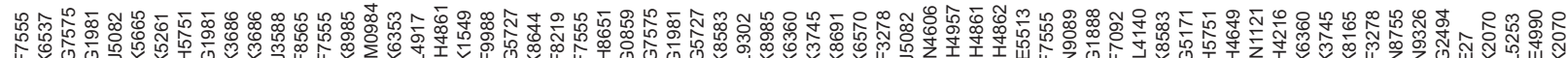

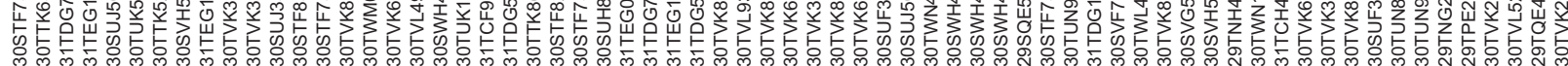

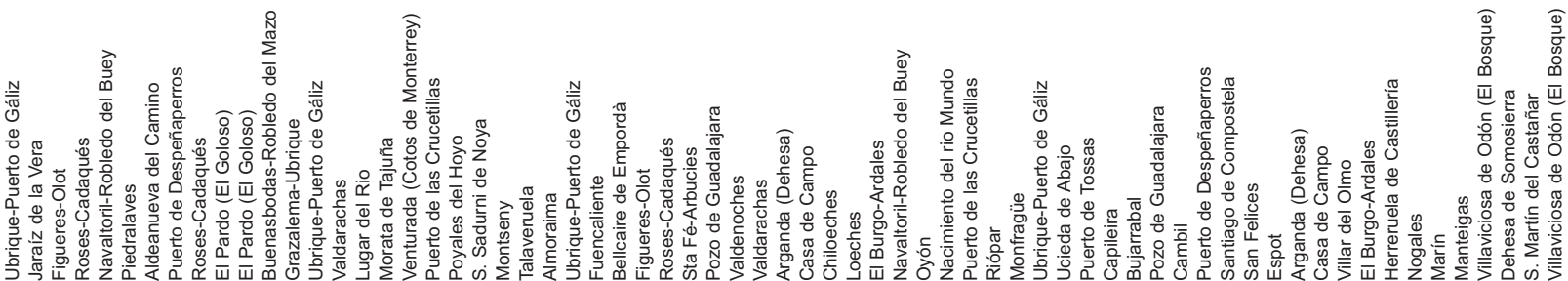

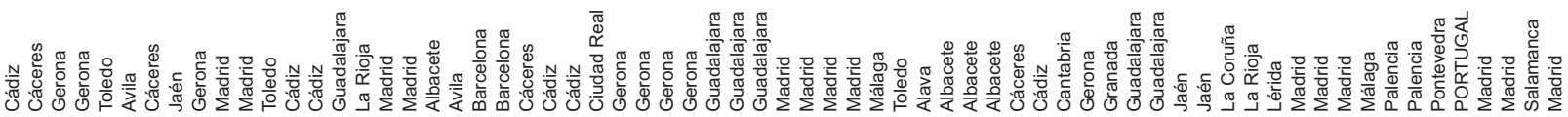

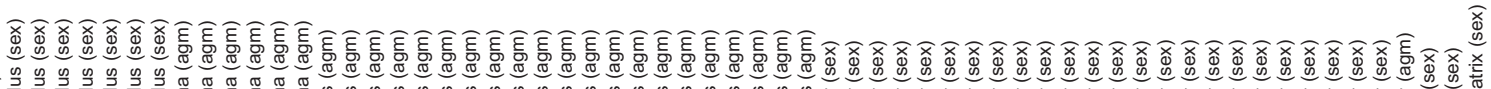

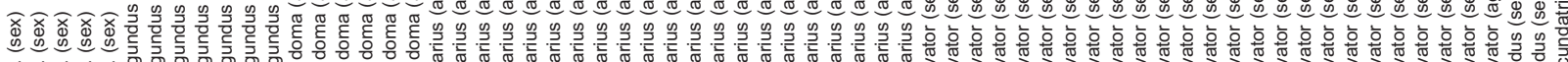

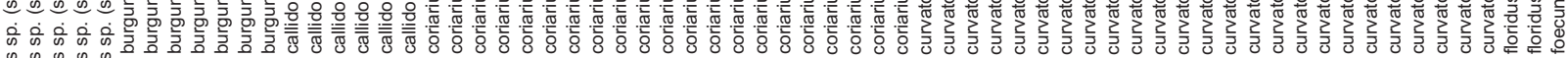

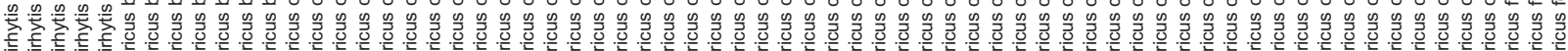

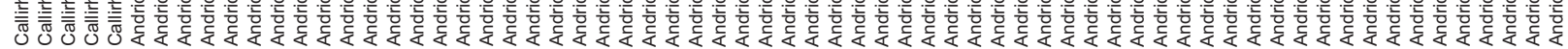




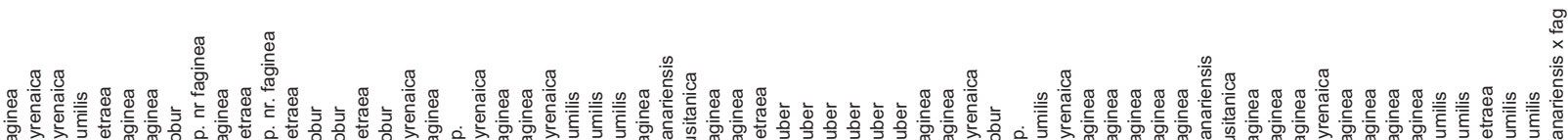

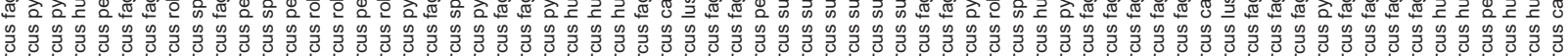
$\begin{array}{lll} & \\ \sigma & & \\ \sigma\end{array}$

毫

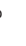




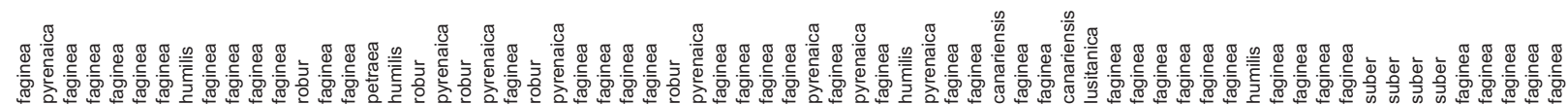

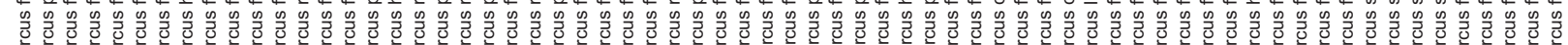
$\begin{array}{lll} & \\ & & \\ 0\end{array}$

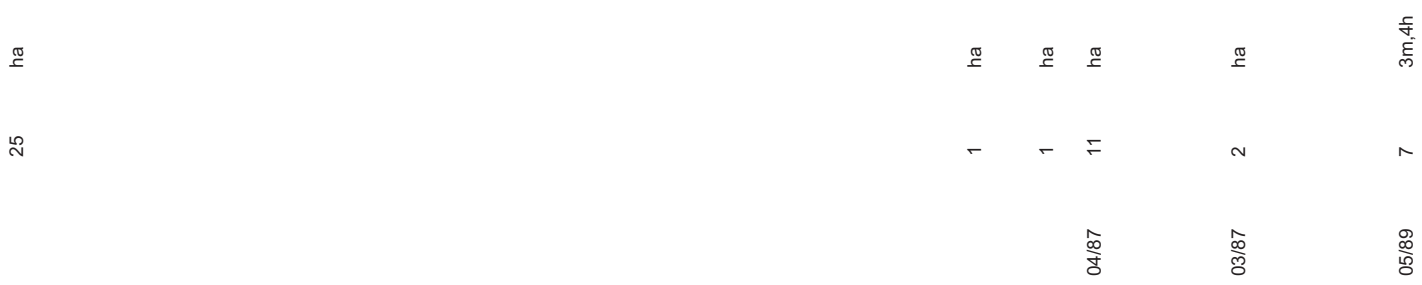

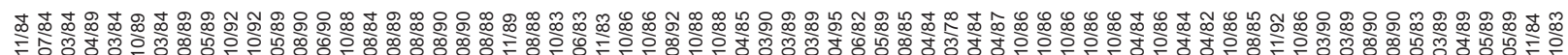

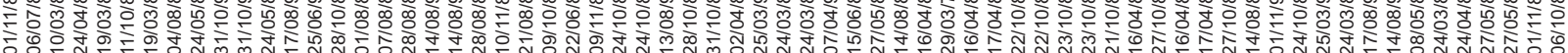

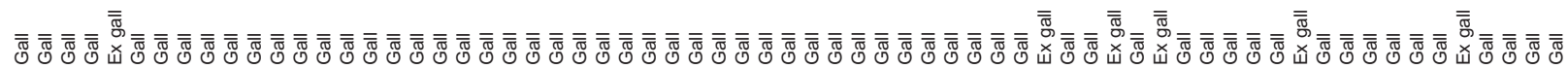

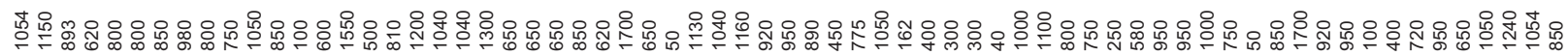

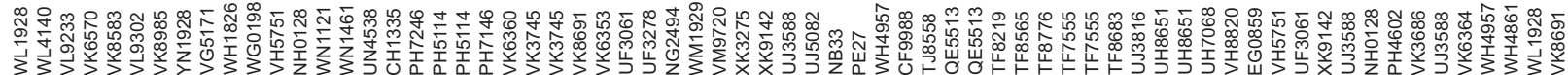

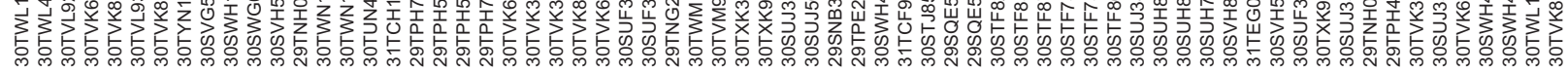

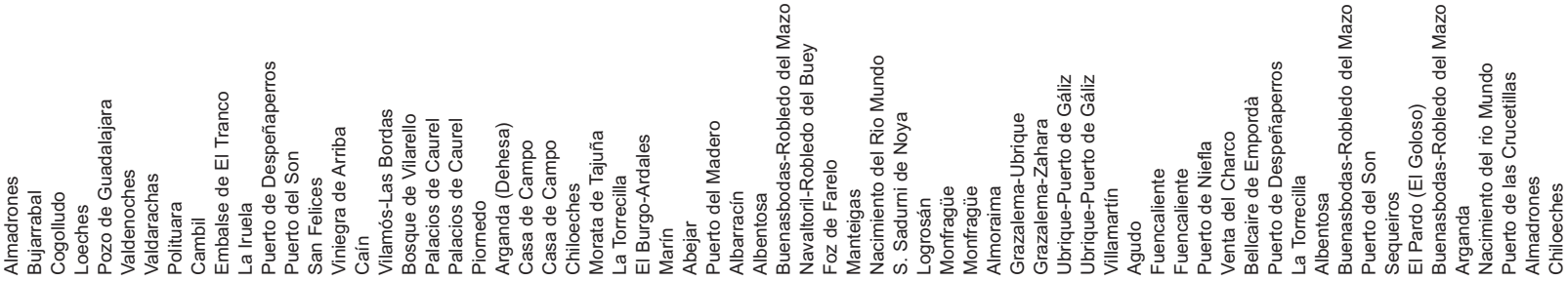
แIIII

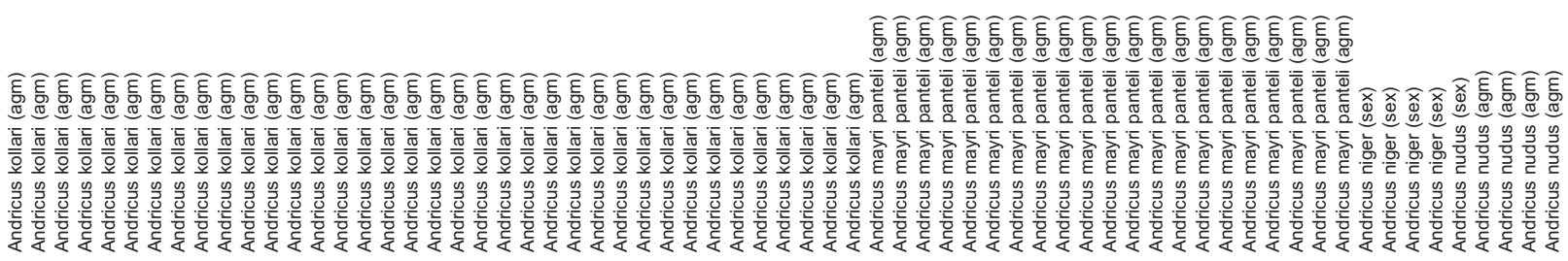




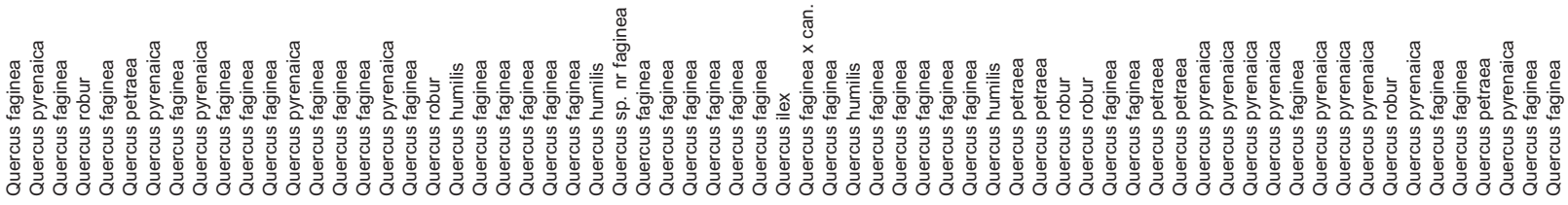

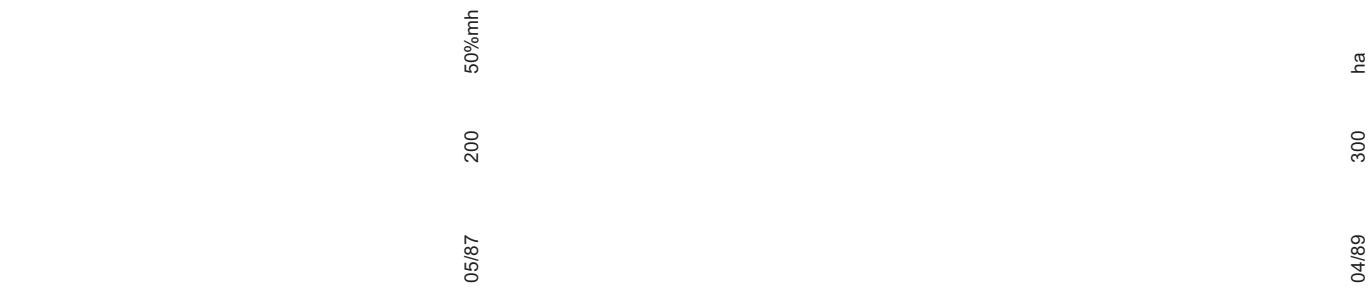

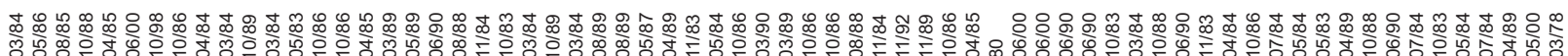

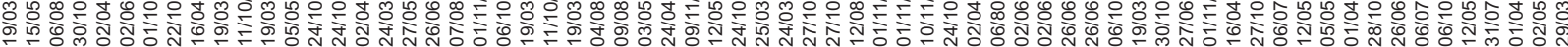

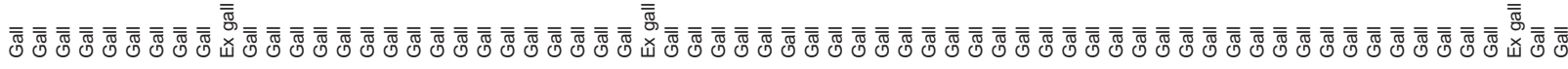

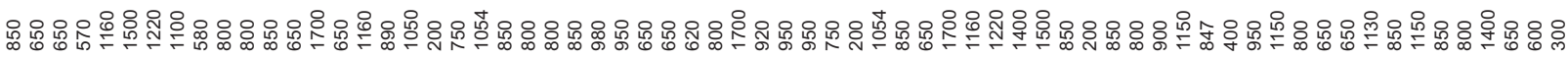

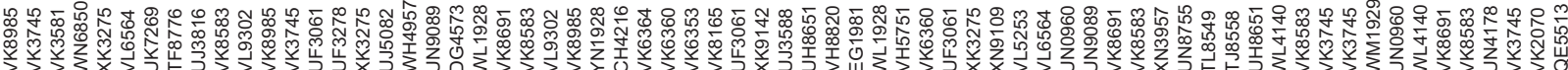

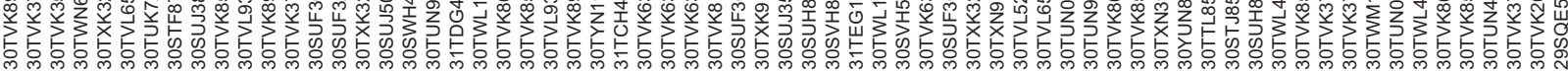

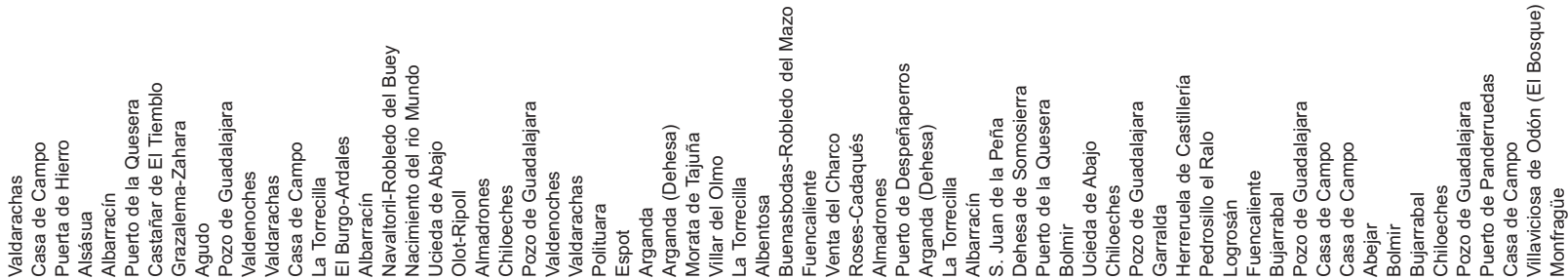

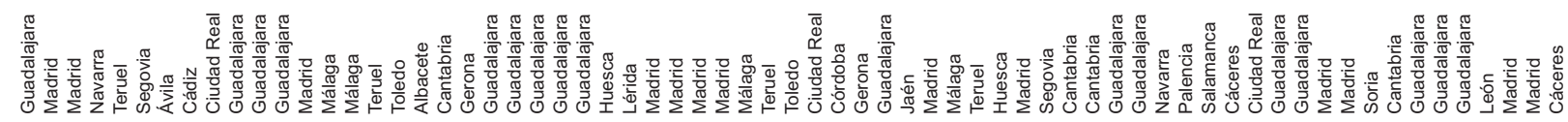

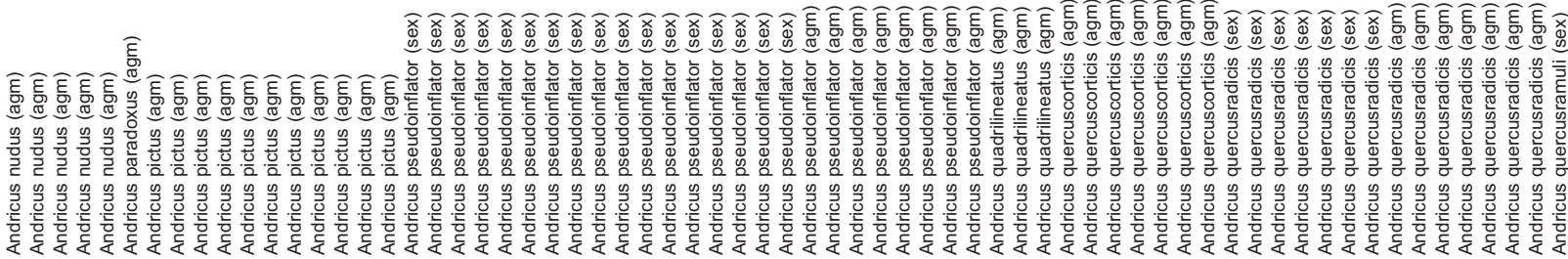




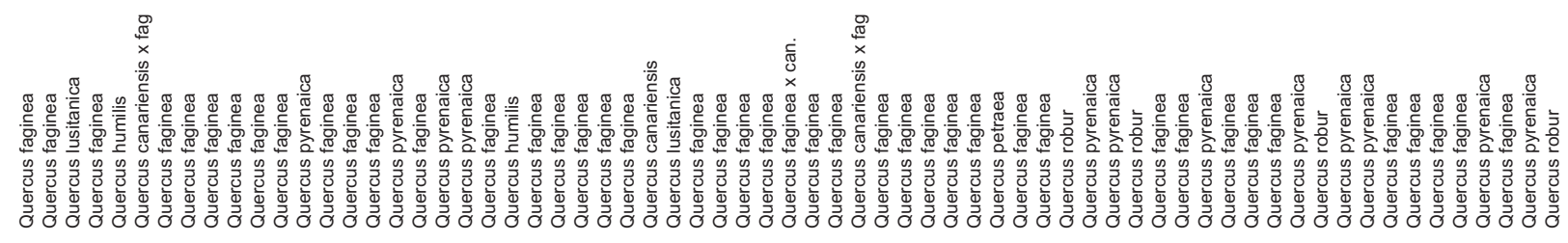

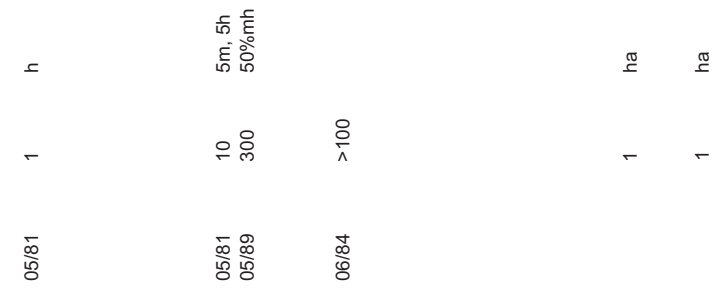

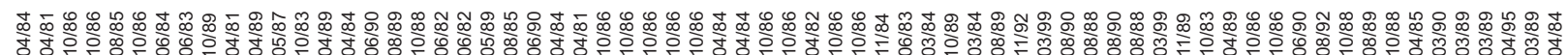

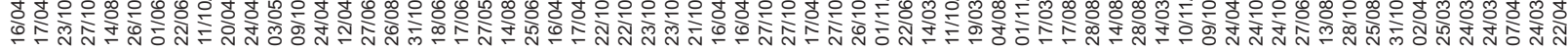

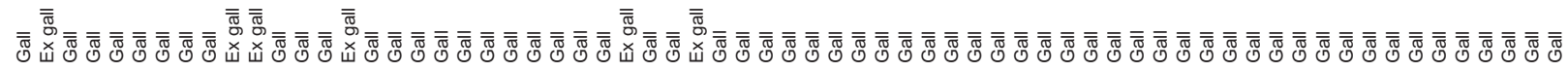

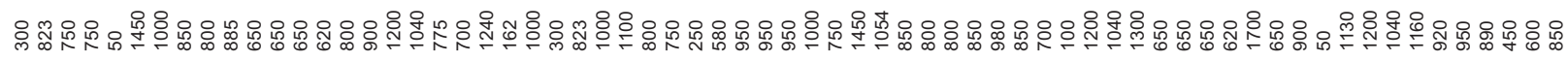

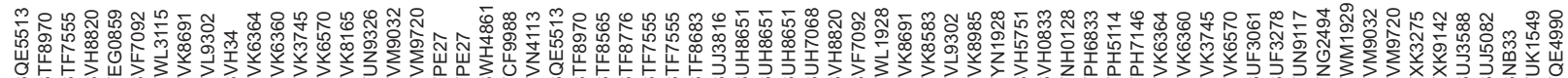

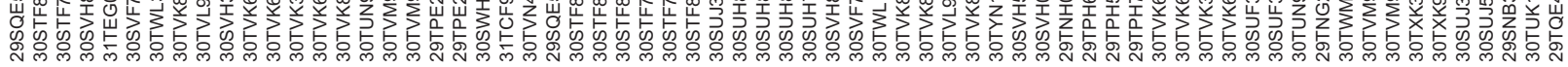

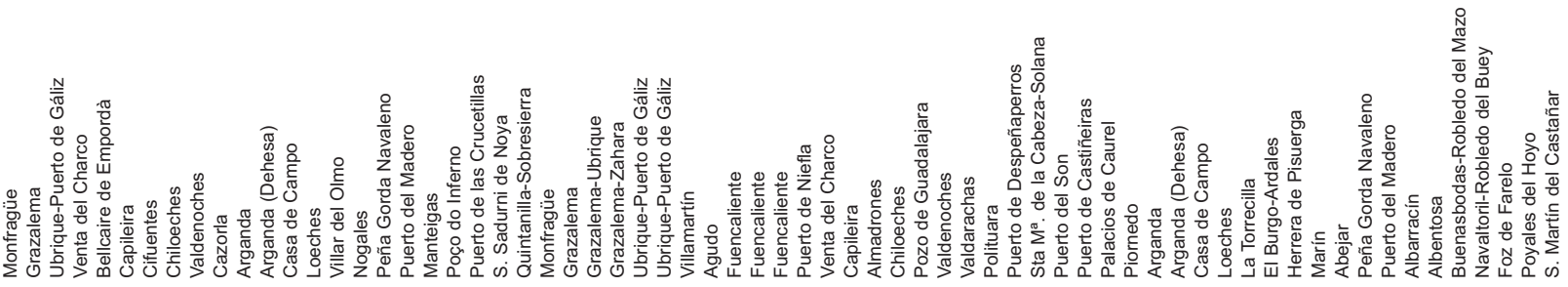

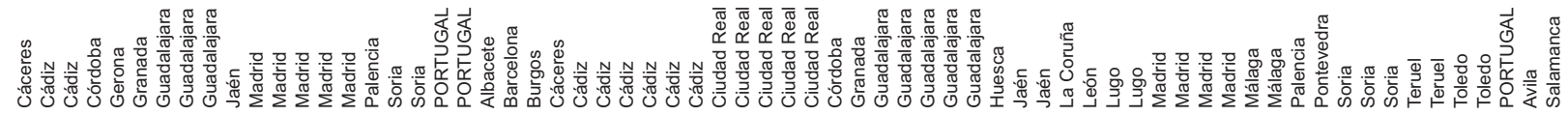

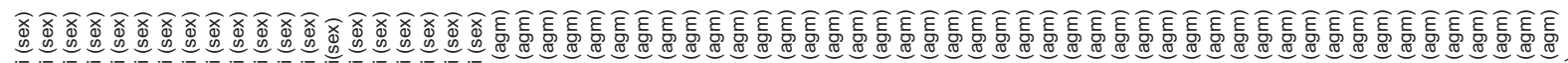

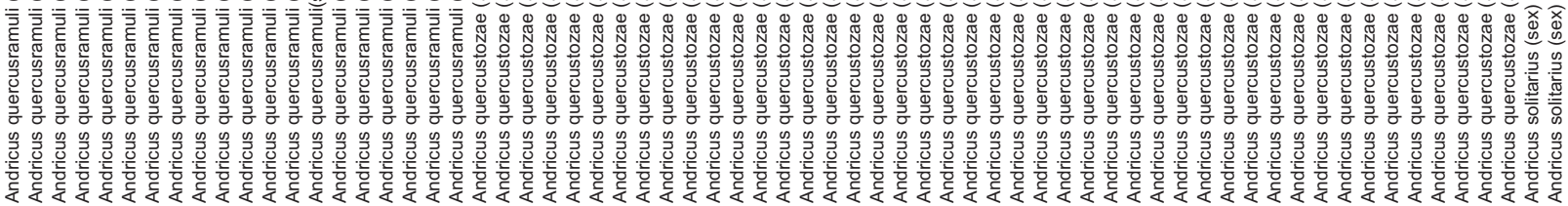




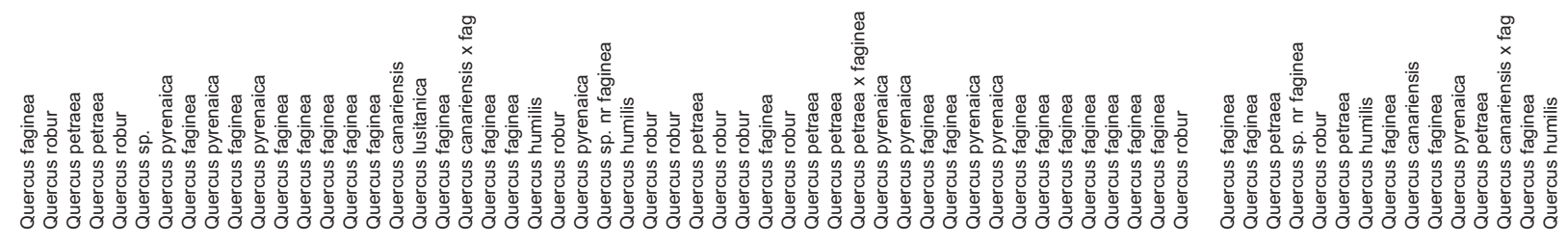

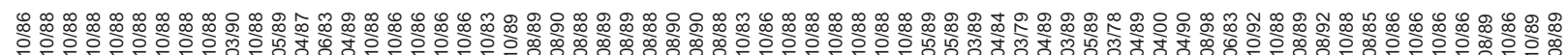

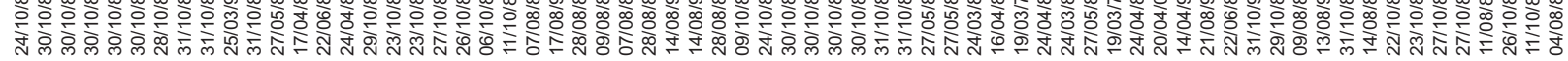

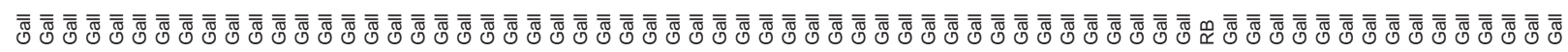

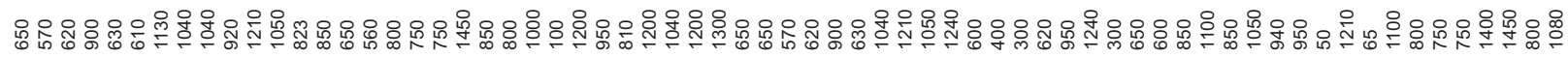

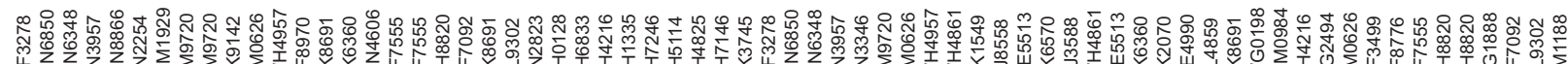

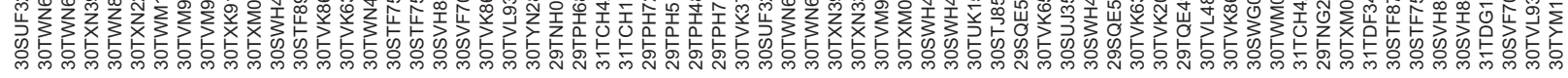

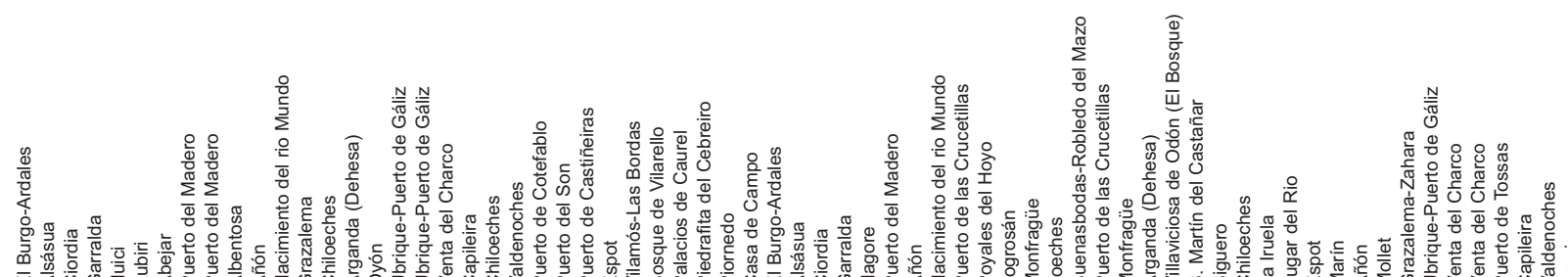

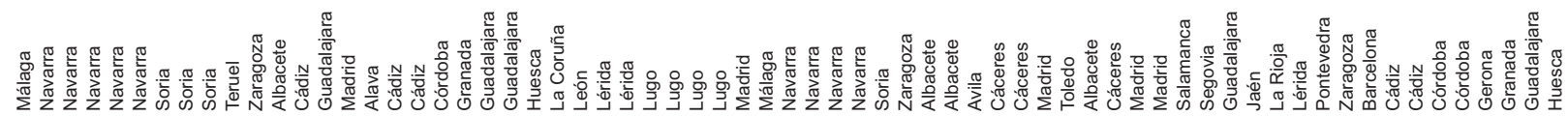

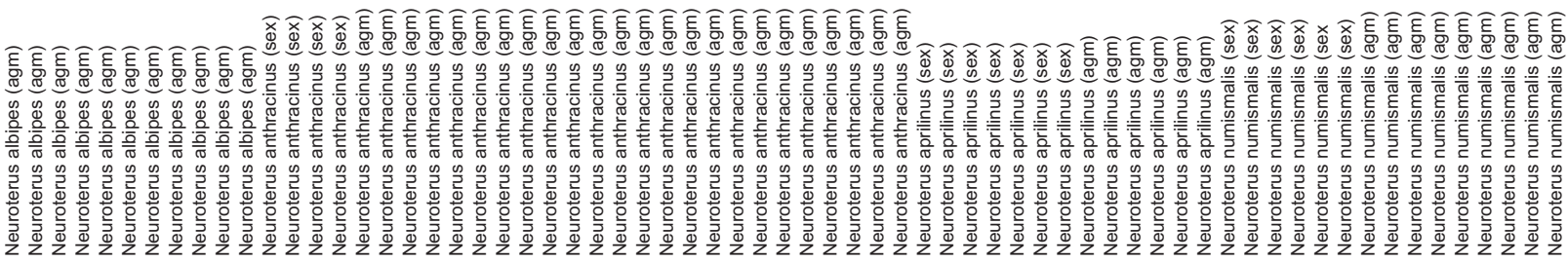




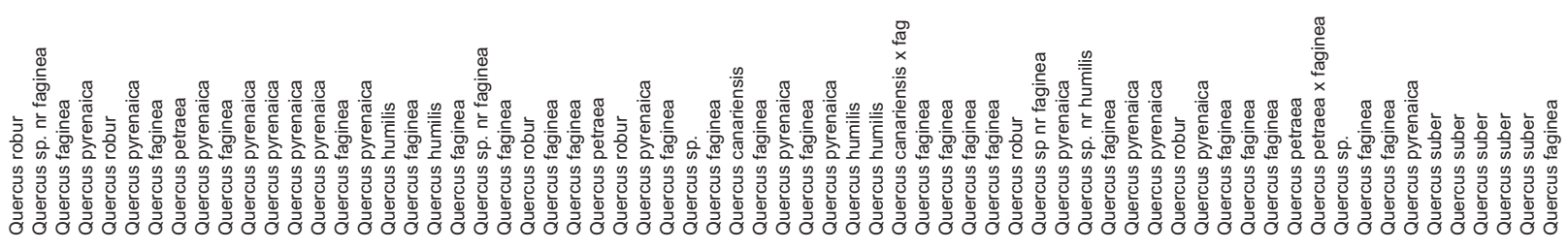

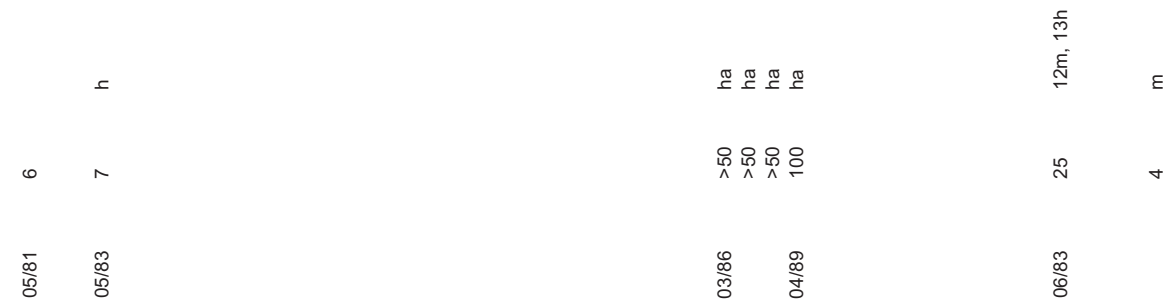

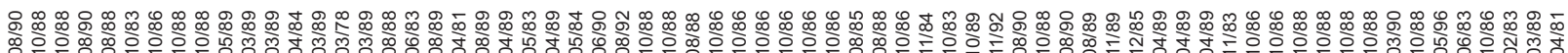

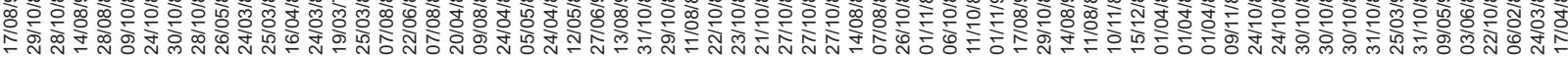

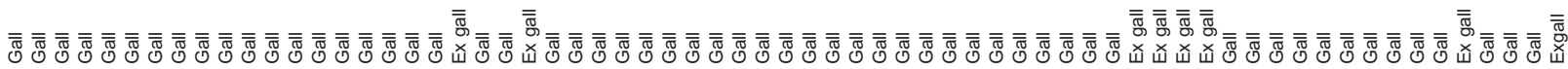

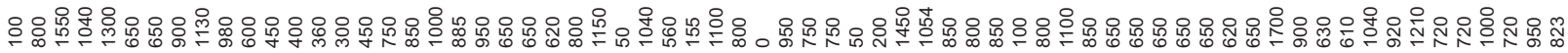

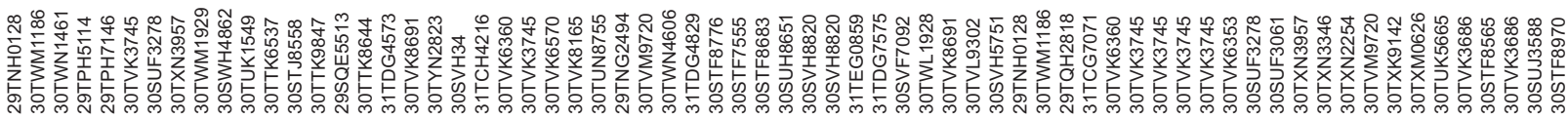

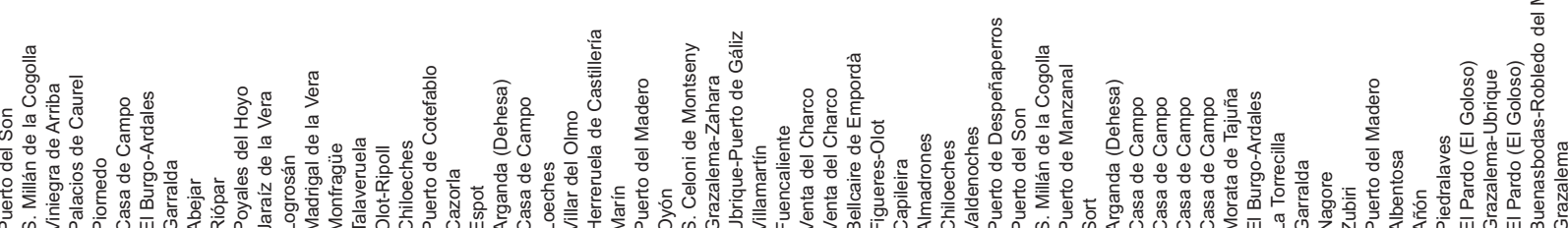
แnt

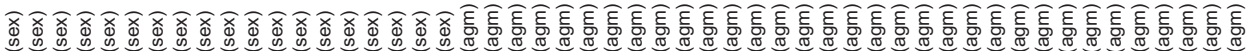

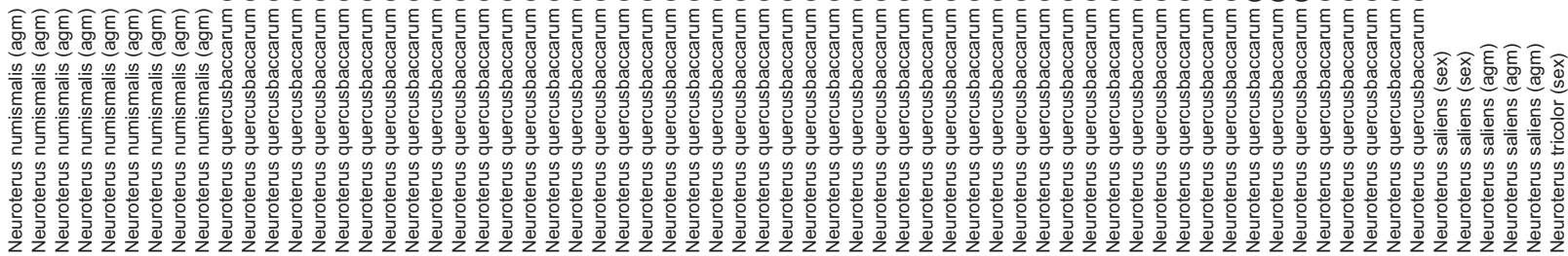




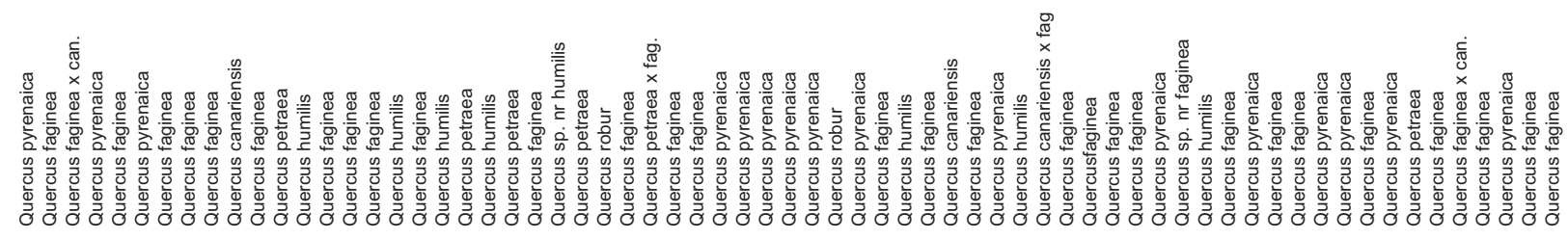

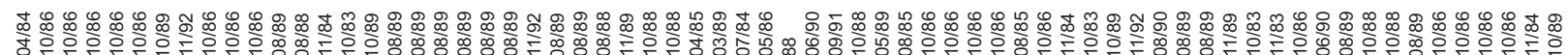

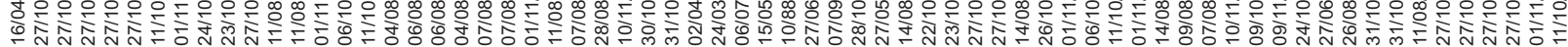

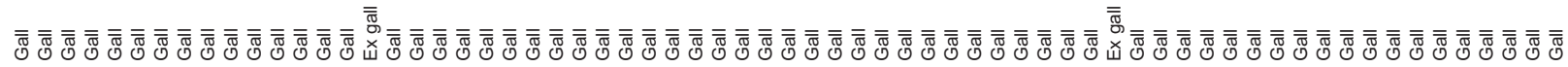

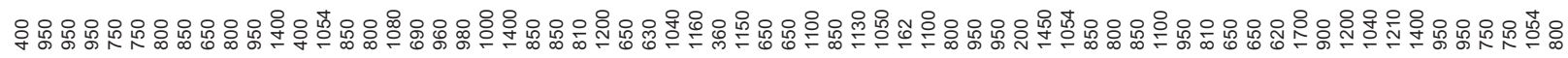

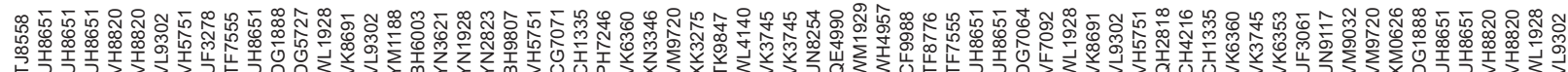

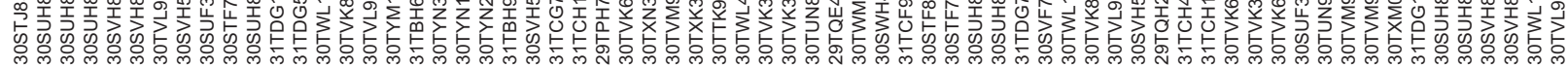

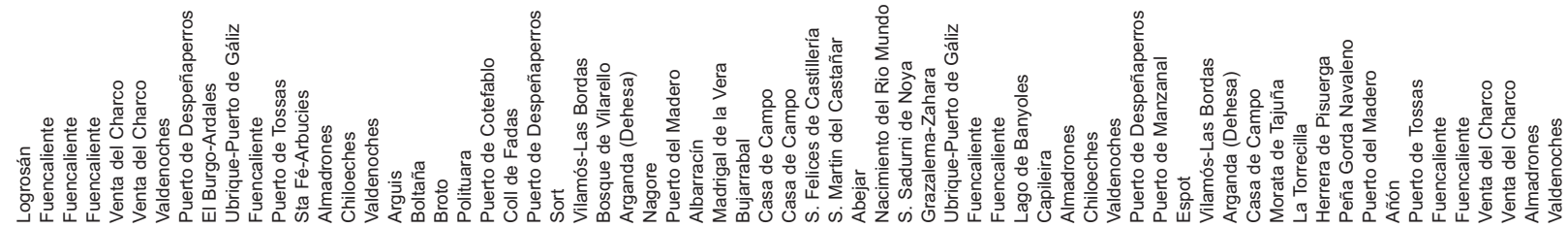

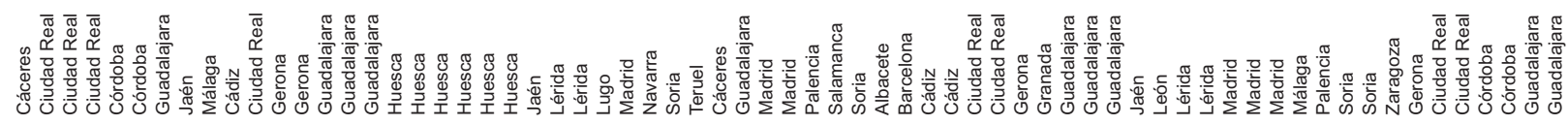

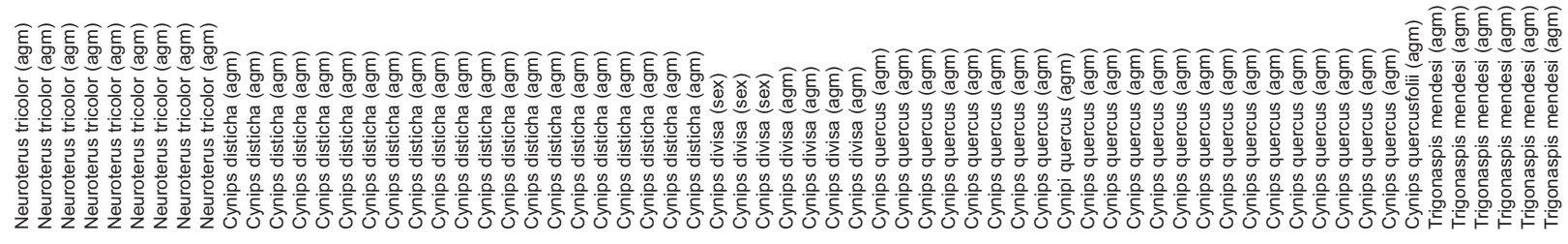




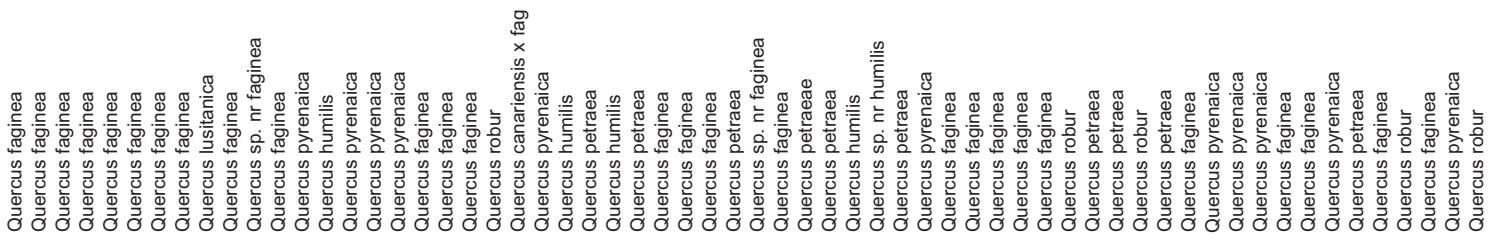

\begin{tabular}{|c|c|c|c|}
\hline & & 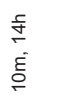 & 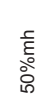 \\
\hline 央 & 员 & & 8 \\
\hline
\end{tabular}

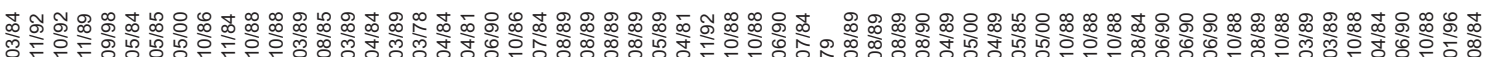

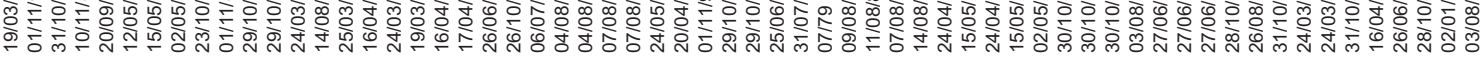

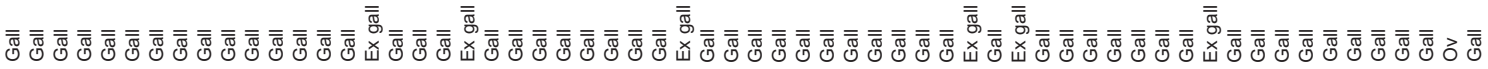

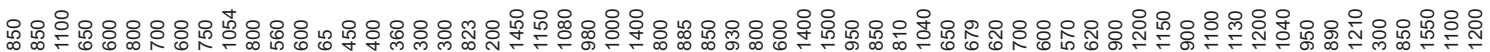

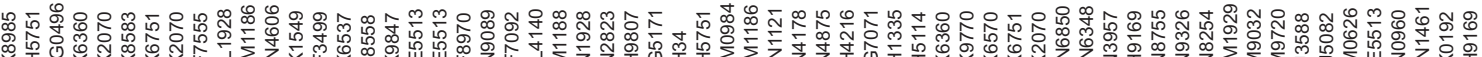

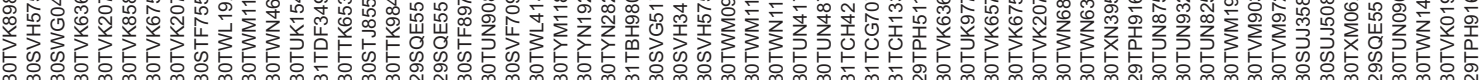

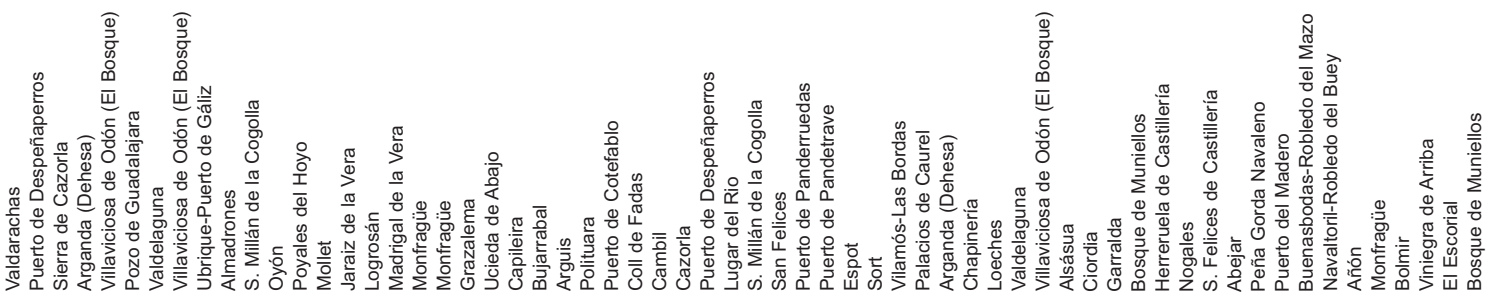

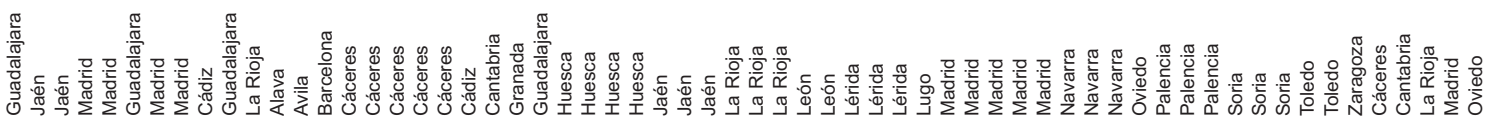

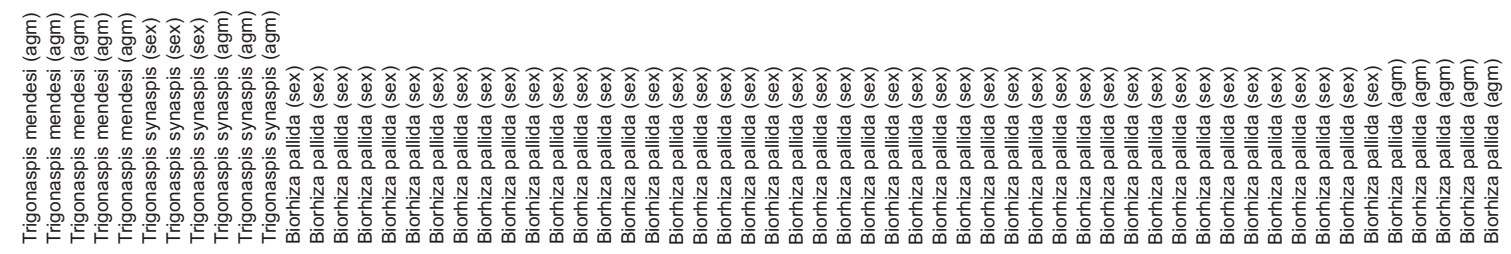

